\title{
Commodity index trading and hedging costs
}

\author{
Celso Brunetti* and David Reiffen**
}

Trading by commodity index traders (CITs) has become an important aspect of financial markets over the past 10 years. We develop an equilibrium model of trader behavior that relates uninformed CIT trading to futures prices. A key implication of the model is that CIT trading reduces the cost of hedging. We test the model using a unique non-public dataset that allows us to precisely identify trader positions. We find evidence, consistent with the model, that index traders have become an important supply of price risk insurance.

JEL classification: G13; C32

Keywords: Commodity Index Traders, Hedging, Limits to Arbitrage

\section{Acknowledgements}

We thank Hannah Ropp and Mehrdad Samadi for outstanding research assistance. We also thank Pat Fishe, Jeff Harris, Steve Kane, Jim Moser, Michel Robe, Aaron Smith, Clara Vega, Hao Zhou, and participants at the CFTC Conference on Commodity Markets and the $18^{\text {th }}$ annual CEF conference in Prague for helpful comments.

\section{Disclaimers}

Disclaimer: The research presented in this paper was co-authored by David Reiffen, a full-time CFTC economist, and Celso Brunetti, who formerly worked part-time as an economist in the Office of the Chief Economist, who is now an full-time employee of the Federal Reserve. This paper was written in their official capacities with the CFTC. The Office of the Chief Economist and CFTC economists produce original research on a broad range of topics relevant to the CFTC's mandate to regulate commodity future markets, commodity options markets, and the expanded mandate to regulate the swaps markets pursuant to the Dodd-Frank Wall Street Reform and Consumer Protection Act. These papers are often presented at conferences and many of these papers are later published by peer-review and other scholarly outlets. The analyses and conclusions expressed in this paper are those of the authors and do not reflect the views of other members of the Office of Chief Economist, other Commission staff, or the Commission itself. Similarly, the views in this paper should not be interpreted as reflecting the views of the Board of Governors of the Federal Reserve System or of any other person associated with the Federal Reserve System. All errors and omissions, if any, are the authors’ sole responsibility.

*Division of Research and Statistics, Federal Reserve Board. Email: Celso.Brunetti@FRB.gov. Address: C St. and $21^{\text {st }}$ St., NW, Washington, DC 20551, US. Phone 202 452-3134.

${ }^{* *}$ U.S. Commodity Futures Trading Commission. Email: dreiffen@cftc.gov. Address: $115521^{\text {st }}$ St., NW, Washington, DC 20581, US. Phone (202) 418-5602. 


\section{Introduction}

In recent years, commodity futures contracts have increasingly become integrated into investment portfolios (Büyüksahin et al., 2009). The amount of money invested globally in commodity indices grew more than tenfold between 2003 and 2008 (CFTC, 2008), and has continued to rise. Commodity index traders (CITs), who have been the main vehicle for investing in commodities, represent a new type of player in these markets (Stoll and Whaley, 2010). Because index traders now represent a large portion of the futures trading, questions have arisen regarding the effect they have on financial markets. For example, the impact of index trading on the cost of diversifying (hedging) is an important policy issue, since diversification is a critical function of futures markets. Masters (2008), Singleton (2014), and others have expressed concerns that index trading contributes to pricing distortions, which can affect hedging costs. In this paper, we study the effect of commodity index trading on financial markets.

The paper provides several contributions to the literature. First, like Acharya, Lochstoer, and Ramadorai (2013), we focus on the determinants of the cost of hedging. This focus seems appropriate, since a key function of commodity futures markets is to allow firms to hedge their inherent risk. We focus specifically on the relationship between CITs and hedging costs.

Using a unique proprietary dataset that precisely identifies the daily trading activity of CITs, we find evidence that the presence of CITs reduces hedging costs, or equivalently, leads to temporary increases in futures returns. ${ }^{1}$ Our results are complementary with that of Acharya,

\footnotetext{
1 This is a unique dataset collected by Commodity Futures Trading Commission which tracks daily positions in each futures contract for each trader, and identifies the line of business of each trader (e.g., CIT, grain distributor, floor trader, hedge funds). Detailed data on commodity index positions only exists for agricultural commodities. Therefore, our empirical analysis is based on agricultural futures markets only. However, our model and our results are rather general and extend to other markets.
} 
Lochstoer, and Ramadorai (2013), who find that increased hedging demand leads to greater returns to long futures positions, or equivalently, a higher price for hedging. ${ }^{2}$

The finding that CITs serve to reduce hedging costs can help inform our analysis of specific CIT behavior in futures markets. As Stoll and Whaley (2010) show, the largest commodity index traders publicly announce the dates on which they roll-over positions from the expiring futures contract to the next maturity futures contract. This sunshine trading provides context for understanding the finding that the regular movements in CITs positions can have predictable consequences for futures prices (e.g., Mou, 2010). To analyze this behavior, we generalize Grossman and Miller (1988) to develop an equilibrium model of trader behavior that relates uninformed CIT trading to futures prices. Theoretical models, dating back to Keynes (1930) and Hicks (1946), have focused on the role of futures markets in allowing firms to hedge their positions in the physical commodity; in particular, agents with inherent long positions in the physical product, such as raw material producers, reduce the riskiness of their portfolios by taking short positions in the futures market. The long side of these trades is taken by speculators, who are willing to hold these futures positions in exchange for positive expected returns. Hence, these models imply that, even absent superior information about futures price movements, speculators will earn positive returns. ${ }^{3}$ These positive returns come about through a futures price that is below the expected spot price at contract expiration — or what is termed backwardation. More formal models, such as those developed by Hirshleifer (1988), de Roon, Nijman, and Veld (2000), and Etula (2013), show that this conclusion remains, even in a model with many risky assets and opportunities for diversification. None of these models, however, are used to study

\footnotetext{
2 Most of the literature on the role of CITs in futures markets concentrates on its effect on futures prices. For a comprehensive literature review on that issue, see Irwin and Sanders (2010).

${ }^{3}$ Empirical studies on whether the source of profits for speculators is information advantages or simply risktaking include Hartzmark (1987), Dewally, Ederington, and Fernando (2010), and Fishe and Smith (2012).
} 
commodity index trading. Instead, these models are based upon the dichotomy between hedgers and speculators [see, for instance, Acharya, Lochstoer, and Ramadorai (2013), Lux (1995), Shiller (2003) and Shleifer and Summers (1990)]. CITs behave differently. Like speculators in these models (and unlike hedgers), CITs have no innate position in the underlying commodity. Unlike speculators, CITs seem to follow simple rules that are unrelated to information: buying and holding long positions in the closest-to-maturity (nearby) contract, which entails their periodically rolling these positions from one maturity to the next, as the nearby contract nears expiration. The premise that their trading is not motivated by superior information is evidenced by their trading rules, which are determined and publically disseminated well prior to the trades being executed. ${ }^{4}$ We use our model to analyze how these traders interact with traditional hedgers and speculators.

One direct implication of our model is that the cost of hedging falls as aggregate CIT positions increase. The intuition behind our theoretical result comes from the premise that CITs are essentially willing to take the opposite position from hedgers at lower prices than are traditional speculators. ${ }^{5}$ More subtle implications of our model relate to the effect of commodity index traders on inter-maturity spreads. As noted, a key characteristic of CITs is that they primarily hold positions in the nearby contract, which usually is the most liquid contract, and periodically roll these positions to the next maturity (first deferred) contract. This exogenous movement of positions between maturities provides a natural experiment with which to examine whether inter-contract spreads vary in the manner implied by the model. In particular, our model implies that the spread between the first deferred and the nearby contract prices depends on both

\footnotetext{
${ }^{4}$ For example, in December of each year, the largest index fund, the Goldman Sachs Commodity Index (GSCI), announces its trading plans for the subsequent year.

${ }^{5}$ According to Stoll and Whaley (2010), they are willing to do so because of the diversification benefit of commodity exposure to their portfolios.
} 
the relative sizes of CIT positions in the two maturities, and on the aggregate size of CIT positions. ${ }^{6}$ More generally, since changes in the prices of contracts of different maturities are not perfectly correlated (and hence are not perfect substitutes from hedgers’ perspectives), CITs' choices of which contracts to invest in will differentially impact prices along the term structure. In addition, the model implies that the size of the effect of CITs on the spread varies with the product cycle; for example, for agricultural commodities, the effect is larger just prior to the harvest, because the correlation between the return on the hedger's cash positions and the nearby futures market is higher. Similarly, in non-agricultural markets, the effect is larger for maturities that expire just prior to seasonal demand peaks, due to higher hedging demand. Finally, the model shows that the spread varies with the size of the cash market position of hedgers.

The final contribution of our paper is to test the hypotheses generated by the model using the highly disaggregate data on trader positions provided by the Commodity Futures Trading Commission (CFTC). Our data precisely identify daily CIT positions. This is the data used by the CFTC for surveillance purposes. An advantage of this data is that there is information on CIT position by contract maturity. This enables us to precisely measure the relationship between futures prices and CITs position in each maturity. One of our key findings is that the intermaturity spread increases with the percentage of CIT holdings in the first deferred contract. This is consistent with the finding elsewhere (e.g., Mou, 2010) that the CIT roll is associated with predictable changes in futures prices. We also find that, as implied by our model, this effect is particularly large later in the harvest cycle or, more generally, when seasonal demand peaks.

As Hirshleifer (1990) shows, changes in hedging demand can only have price effects when supply is less than perfectly elastic. Our finding that the relative prices of different

\footnotetext{
${ }^{6}$ Examining the effect of trader behavior on inter-maturity spreads is a powerful test of our model, because taking differences mitigates the noise introduced by changes in market fundamentals.
} 
maturities vary predictably with CIT positions is consistent with the premise that liquidity providers have less-than-perfectly-elastic supply curves.

Although our analysis focuses on commodity futures markets, this finding can shed light on issues relevant to equities and, in particular, to equity indices. Just as commodity index funds change their portfolios as contract expiration nears, equity index funds change their portfolios in response to publicly observable events. In particular, there is a considerable literature showing that the addition of a stock to a major index increases its share price (e.g., Shleifer, 1986; Harris and Gruel, 1986; Greenwood, 2005). One interpretation of this phenomenon, which is consistent with the model developed here, is that the redefinition of the index leads to an increase in the demand for that stock, as some mutual funds are contractually obligated to have a portfolio that is representative of a specific index. Thus, the increased share price results from the interaction of this higher demand with a less-than-perfectly elastic supply of existing shares of individual stocks. ${ }^{7}$ A second interpretation is that the greater trading volume caused by mutual funds adding the stock to their portfolios creates a more liquid market for the stock, leading to lower bid/ask spreads, and thereby increasing its price (e.g., Dhillon and Johnson, 1991). A third explanation is that the addition of the firm to the index represents real information about the long-term prospects of the stocks [e.g., stocks added to the index are, ceteris paribus, less likely to face bankruptcy, see Jain (1987)]. As noted above, the timing of the roll by major CITs is announced well in advance. Hence, it would seem that there is no information about fundamental values in these trades, and any price change observed at the time CITs actually trade must reflect some other mechanism.

\footnotetext{
7 The interpretation that the higher cost reflects a less-than-perfectly-elastic supply of a stock is analogous to the model developed here, in which the higher price is due to a less-than-elastic supply of price risk insurance.
} 
We proceed as follows. In Section 2, we describe the Large Trader Reporting System that is used to collect data on trader positions. In Section 3, we empirically test whether the size of CIT positions affects hedging costs, and find that larger CIT positions reduce hedging costs. This finding motivates the development of a model of uninformed trading and price behavior in Section 4. We test the model in Section 5 and conclude in Section 6.

\section{Trader positions}

We use daily position data for three agricultural futures markets. Since these data differ from those used in many other studies, we describe the data in some detail. The position data come from the U.S. CFTC's Large Trader Reporting System (LTRS). This non-public database contains end-of-day positions for each large trader, where large is defined as having a position greater than some threshold number of contracts, with the threshold differing across contracts. ${ }^{8}$ Large traders typically represent about $70 \%-75 \%$ of the open interest in the contracts evaluated in this study. The LTRS reports the long and short positions of each large trader in each maturity futures contract, including the delta-adjusted options positions. We examine data for the July, 2003 through November, 2012 period.

Our data have several advantages over the more aggregate data that are publicly available, and have been used elsewhere (e.g., Stoll and Whaley, 2010). First, we use daily data, while the publicly-available data are weekly observations. Second, our data are disaggregated by maturity. In combination, these features allow us to more accurately measure movements of individual trader's (or groups of traders) positions between maturities, and hence estimate the

\footnotetext{
${ }^{8}$ For wheat, for example, a large trader is defined as someone who has a position of more than 150 contracts.
} 
effect of hedger and CIT positions in specific maturities on prices and on inter-maturity spreads. ${ }^{9}$ Finally, our data are available at the individual trader level, which, as discussed below, allows us to measure CITs over a longer period of time, and to aggregate traders into smaller and more homogeneous categories.

To see the utility of this greater granularity, note that in addition to reporting their futures and options positions, traders self-report their lines of business. Table 1 lists the nine trader categories that are important in agricultural products, along with the average number of traders and average net positions of all large traders (summed across maturities) in each category for the three most actively-traded field crops. Large traders in the first five categories are involved in some aspect of the grain industry (and are denoted commercial traders), and it is likely that their positions primarily reflect a desire to reduce their inherent risk (i.e., they are hedgers). Of these, roughly $70 \%$ of commercial traders are categorized as owners of grain storage facilities (category AD, whom we refer to as agricultural distributors). Such firms typically acquire long positions in physical grain, and therefore take short positions in futures markets to hedge their price exposure. Hence, the futures market positions of these traders are natural reflections of their underlying business. As indicated in Table 1, short futures positions by distributors represent nearly $30 \%$ of open interest in wheat, corn, and soybeans. The last category of commercial traders is swap dealers, who often use the futures market to hedge the risk arising from its swap activity. Similar to manufacturers (AM) and producers (AP), swap dealers are less likely to be systematically on one side of the market. Thus, distinguishing distributors from the other commercial traders provides us a more accurate measure of hedging behavior than studies

\footnotetext{
${ }^{9}$ Having data at the individual maturity level has been shown to yield insights into trader behavior and its implications for markets. For example, Buyuksahin, et al. (2009) show that swap dealers in crude oil hold different positions in different maturities; they are long in near-dated contracts, and short in more distant ones. The authors are interesting in determining the effect of swap dealers on near- versus far-dated prices, and hence the more granular data are critical to their analysis.
} 
based on aggregate statistics, such as Bessenbinder (1992), de Roon, Nijman and Veld (2000), and Gorton, Hayashi, and Rouwenhorst (2012).

There are other participants in futures markets who have no innate position in the physical commodity and are referred to as non-commercials (speculators). The non-commercial category Floor Brokers and Traders (FBT) consists of traders who have no physical presence in the industry, but instead take long or short positions in order to take advantage of what they view as favorable prices (these traders are sometimes referred to as locals). They typically make bids and offers on the same day, serving as market makers by effectively providing liquidity to other market participants. The other two categories of non-commercial traders, MMT and NRP, are more heterogeneous sets of traders, but include firms that manage investment portfolios, often referred to as hedge funds.

Like other non-commercial traders, CITs have no physical presence in these agricultural markets. This category is different from the other categories in that it is not self-reported. Instead, it reflects an effort by the CFTC to develop statistics to monitor an important change in agricultural futures markets. Specifically, as commodity index traders began to hold a larger portion of open interest, the CFTC as well as many industry participants, became interested in enhanced tracking of the positions of these traders. Accordingly, in 2006, the CFTC reclassified some traders into this new category, based on their behavior in 12 agricultural futures markets. There was no corresponding reclassification in other futures markets, such as energy or metals. One reason for the differential treatment was that many traders in these other futures markets simultaneously act as index traders and swap dealers [see the discussion in the CFTC (2006b) and Cheng, Kirilenko and Xiong (2012)], and it is difficult to isolate a pure CIT position. Hence, the clearest picture of the effect of CIT trading occurs on agricultural markets, and consequently, 
we focus on the three largest agricultural markets. However, our model and empirical methodology are general and also apply to other markets.

The determination of which traders constitute CITs is based on identifying all traders with large long positions in agricultural futures contracts and evaluating whether the trades made by those firms were consistent with index trading, as well as a series of interviews with these traders (CFTC, 2006a). ${ }^{10}$ We categorize traders as CITs throughout the sample if they met the CIT criteria as of 2006 (as discussed below, the evidence suggests this treatment is appropriate). Once CITs are identified, we can track their positions back to dates prior to 2006. This allows us to have a longer time series of observations on CIT behavior. Figure 1 presents some evidence on the relative importance of CITs in the corn market. The y-axis represents the largest end-ofday position held by CITs in each nearby contract, as a percentage of total open interest on that date. CITs' long positions in the nearby corn futures contract represented about $25 \%$ to $30 \%$ of the total open interest in 2003. The percentage grew fairly consistently through late 2006, and then fell gradually over the second half of the sample. One noteworthy aspect of this pattern is that 2006 does not represent a structural break in the series; instead, CITs' aggregate position in 2006 seems to be a continuation of the previous trend. The history of CIT positions in soybeans and wheat is quite similar.

\section{The price of hedging}

The traditional view of futures markets is that they allow traders with innately risky positions to hedge that risk. The canonical example is a grower who owns crops that will mature

\footnotetext{
${ }^{10}$ Cheng, Kirilenko, and Xiong (2012) find that trading behavior by traders within the CIT classification corresponds to the passive, buy-and-hold investors we model in agricultural products, but less so in other futures markets, such as metals and energy products. This again suggests that pure index trading is more likely to be observed in agricultural futures markets.
} 
at some future date, and consequently, faces price risk until the crop is sold. By taking a short position in the futures market in that commodity, this grower is able to essentially sell the crop earlier in the season, and thereby reduce her exposure to price risk over the production horizon. Her counterparties on the futures market may also be reducing their risk. That is, by taking a long position in the futures market, a firm that plans to buy the crop after it matures (like a flour mill) can likewise reduce its exposure to price risk by buying the crop in advance. If these two kinds of hedgers are the only traders, then the futures price of the crop would reflect the relative demands of the two groups. However, the price that clears the market when only hedgers are present may be sufficiently high or low (relative to the expected spot price) that traders with no innate interest in the commodity may find it profitable to trade on one side of the market. The premise of the theory of normal backwardation, advanced by Keynes (1930) and Hicks (1946), is that the relative demands of long and short hedgers are such that the futures price will be below the corresponding expected future spot price (i.e., short hedging demand exceeds long hedging demand). More recent work, such as Hirshleifer (1990), de Roon, Nijman, and Veld. (2000), and Etula (2013), extends this framework to consider a broader set of portfolio options for speculators. ${ }^{11}$ The basic conclusion remains that assets (such as futures) that have a positive correlation with the innate risk held by firms will have a positive return to long positions.

While the sign of the net position of all hedgers could conceivably vary across markets, the evidence is that for most commodities, hedgers are net short in the futures market. For agricultural commodities, the largest group of hedgers is distributors, who have innate long positions in physical agricultural products. In fact, for the three products we study, these distributors hold a much larger absolute share of open interest than any other group, as shown in

\footnotetext{
11 Gorton, Hayashi, and Rouwenhorst (2012) look at backwardation in a model with physical inventories. They show that the price of hedging is decreasing in inventories.
} 
Table 1 . Their physical market positions typically consist of forward agreements with growers to buy crops at set prices, as well as crop inventories. Evidence on cash market positions in agricultural commodities also suggests that traders with long physical market positions hedge, by taking a short positions in the futures contract, much more often than do traders with a short physical position (Brunetti and Reiffen, 2014). More generally, because hedgers as a group tend to be short on net in most commodity futures markets, speculators primarily take the long side, as implied by the backwardation model.

Put differently, one can think of the cost of hedging as the equilibrium discount (from expected spot prices) hedgers accept in order to avoid price risk. A positive discount implies that the party who is short in the futures contract loses money, on average, on that contract. However, for an agent who has a pre-existing long position in the physical product (and therefore hedges by taking a short futures position), that cost can be justified by the reduction in the variability of returns. ${ }^{12}$ In this sense, hedging is a form of insurance.

The price of this insurance can then be modeled in terms of demand and supply. In Acharya, Lochstoer, and Ramadorai (2013), demand for hedging is modeled as reflecting the risk aversion of producers (who hedge), while supply reflects the financing constraints on speculators. They find evidence that an increase in hedging demand due to higher default risk increases the price of hedging. While the extent of risk aversion affects the price of hedging in the model we present in Section 4 as well, we focus on changes in the hedgers' innate position in the underlying as a cause of demand shifts. The key point of departure, however, is our focus on changes in CIT positions as a source of supply shocks. ${ }^{13}$ In either case, however, the less-than-

12 Of course, a premium over the expected spot can be consistent with hedging, if hedgers are on net short in the physical, and hence long in the futures market. As noted, CFTC data show that hedgers are primarily short in the futures markets, which suggests they are long in the physical product.

${ }_{13}$ Singleton (2014) provides evidence that changes in hedging supply have had significant effects on prices in crude oil futures markets. 
perfectly elastic supply (limit to arbitrage) means that demand changes lead to price changes. As Hirshleifer (1988) emphasizes, different assumptions about the elasticity of supply of insurance yield different implications regarding the relationship between hedger characteristics and the cost of insurance. In line with Acharya, Lochstoer, and Ramadorai (2013) our findings imply that hedging supply is less than completely elastic.

Our empirical investigation focuses on the relationship between hedging costs and CIT supply/hedger demand, and we measure the cost of hedging at time $t$ as:

$$
\left(E_{t}\left(P_{T}\right)-P_{t}\right) / P_{t},
$$

where $P_{t}$ is the futures price on day $t$, and day $T$ is the expiration date of the futures contract. Based on the usual arbitrage argument, we assume that futures and spot prices converge on the expiration date, so that $E_{T}\left(P_{T}\right)$ is equal to the expected spot price on date $T$. While $E_{t}\left(P_{T}\right)$ is not directly observable at every $t, E_{T}\left(P_{T}\right)$ is observable. Moreover, $E_{T}\left(P_{T}\right)$ is an unbiased estimate of $E_{t}\left(P_{T}\right)$ for each contract. Of course, this does not mean that $E_{t}\left(P_{T}\right)$ will not vary over time. In particular, hedging costs may depend on i) the state of the economy, ii) the perceived riskiness of economic conditions, iii) the volatility of the futures contracts, iv) the risk-free rate, and v) the time to maturity (see Acharya, Lochstoer, and Ramadorai, 2013). Thus, to test whether the price of hedging is decreasing in CIT positions and increasing in hedger cash positions, for each of the 47 contracts (i) and for each of the three commodities $(j)$ in our sample, we first run a regression of the form:

$$
\begin{gathered}
\frac{E_{T, i, j}\left(P_{T, i, j}\right)-P_{t, i, j}}{P_{t, i, j}} \equiv Y_{t, i, j}= \\
b_{0, i, j}+b_{1, i, j} Y_{t-1, i, j}+b_{2, i, j} \Lambda_{t, i, j}+b_{3, i, j} V_{t, i, j}+b_{4, i, j} r_{t}+b_{5, i, j} A D S_{t}+b_{6, i, j} D S_{t}+\varepsilon_{t, i, j}
\end{gathered}
$$


The left-hand side variable, $Y_{t, i, j}$, is the cost of hedging for product $j(j=$ wheat, corn, soybeans) in contract $i(i=1,2, \ldots, 47)$, at time $t$. In equation (1), three variables are specific to the contract while the remaining three capture general economic factors. Specifically, $b_{1, i, j}$ accounts for the autoregressive component in the cost of hedging, $\Lambda_{t, i, j}$ represents the days to maturity of the contract and captures the cyclicality of futures contracts, and $V o l_{t, i, j}$ is the daily volatility of the contract, which is computed as the difference between the daily high and low prices in log (Garman and Klass, 1980). We expect the cost of hedging to be increasing in the volatility of the futures price. Hedging costs should also be increasing in the risk-free rate $\left(r_{t}\right)$. We include the Aruoba-Diebold-Scotti $\left(A D S_{t}\right)$ business conditions index published by the Philadelphia Federal Reserve Bank to account for commodity demand. One way in which current business conditions may affect hedging cost is through inventory. Higher current demand means lower current inventory, and hence lower hedging demand, which in turn implies lower hedging costs. This suggests a negative relationship between ADS and the price of hedging. We also include the default spread $\left(D S_{t}\right)$ measured as the difference between the Baa- and Aaa-rated corporate bond yields (Acharya, Lochstoer, and Ramadorai, 2013 ). The default spread proxies for default risk in the economy and has been shown to forecast excess returns on stocks and bonds (e.g., Fama and French, 1989; Jagannathan and Wang, 1996). The coefficients of primary interest are $b_{0, i, j}$, which measure the average hedging cost at the median date during the period in which that maturity is the nearby, and the standard deviation of the error term, $\sigma_{\varepsilon, i, j}$, which represents the volatility of hedging cost. Of particular interest is how $b_{0, i, j}$ and $\sigma_{\varepsilon, i, j}$ vary with the demand and supply of insurance. Hence, our second stage regressions are:

$$
\begin{aligned}
& b_{0, i, j}=a_{0, j}+a_{1, j} I_{i, j}+a_{2, j} C_{i, j}^{a g g}+\sum_{k=1}^{3} a_{2+k, j} F F_{i, j}^{k}+v_{i, j} \\
& \sigma_{\varepsilon_{i, j}}=w_{0, j}+z_{1, j} I_{i, j}+z_{2, j} C_{i, j}^{a g g}+\sum_{k=1}^{3} z_{2+k, j} F F_{i, j}^{k}+\xi_{i, j},
\end{aligned}
$$


where $I_{i, j}$ is our measure of CIT positions in product $j$ in contract $i$, and $C_{i, j}^{a g g}$ is our measure of the cash positions of agricultural distributors in the underlying commodity, computed as the median value of those positions over the period of time during which the contract is the nearby. ${ }^{14}$ $F F_{i, j}^{k}$, with $k=1,2,3$, refers to the correlation between the three Fama-French factors and the cost of hedging from equation (1) and is used to control for other risk factors. The implication of the backwardation model is that $a_{1, \mathrm{j}}$ and $z_{1, \mathrm{j}}$ should be negative while $a_{2, \mathrm{j}}$ and $z_{2, \mathrm{j}}$ should be positive.

We estimate equation (1) using OLS, with Newey-West standard errors, for each of the 47 maturities of each commodity. ${ }^{15}$ About $70 \%$ of the coefficients from these regressions are statistically significant at the $10 \%$ level (see Supplemental Appendix for details). The bulk of the significant coefficients have the anticipated sign. For example, in $61 \%$ of cases, the estimated coefficient on the volatility is positive and significant. Similarly, the results for $b_{2}, b_{4}$, and $b_{6}$ are consistent with our expectations; the hedging discount is generally increasing in $\Lambda_{t, i, j}$, the riskfree rate, and the default spread. The least consistent variable is ADS. While $b_{5}$ is almost always negative whenever it is significant (nearly $90 \%$ of the time), as we expected, it is significant in only about half of the regressions in equation (1) across the three commodities. The fact that $b_{5}$ is often not statistically significant indicates that it incorporates a variety of factors, some of which may imply a positive relationship between ADS and hedging costs. Overall, the average $\mathrm{R}^{2}$ is over $60 \%$, indicating that the regressions are explaining most of the variation in the cost of hedging. Finally, standard $t$-statistics indicate that the regressions in the first step are wellbehaved.

\footnotetext{
14 We treat $I$ as constant in each contract. In fact, as shown in Figure 3, the aggregate position of CITs varies little over the course of the contract.

15 There are 40 to 80 observations in each regression.
} 
Table 2 presents our estimates of the regressions in equations (2) and (3). Standard errors are bootstrapped (e.g., Varian, 2005). In our estimates of equation (2), for all three commodities, the average cost of hedging, $b_{0}$, is increasing in $C^{a g g}$, and decreasing in $I$, as suggested by the backwardation model. To interpret the coefficients, consider the effect of a one standard deviation increase in $I$. For wheat, a one standard deviation increase in CIT positions represents a change of about 50,000 contracts, which the model implies will reduce hedging costs by 1.5 basis points, or about one-third of the mean hedging cost. The market factor $\left(F F_{i, j}^{1}\right)$ is always positive and significant across the three commodities, indicating that the higher the market risk, the higher is the average cost of hedging. The remaining two Fama-French factors are never significant.

Estimation results for equation (3) show that the variance of hedging costs is increasing in $C^{a g g}$ and decreasing in $I$, with $C^{a g g}$ in the corn and in the soy regressions having the greatest statistical significance. The $\mathrm{R}^{2} \mathrm{~s}$ are considerably higher than in our estimations of equation (2). ${ }^{16}$

These results indicate that index traders provide insurance for hedgers in agricultural markets, thereby reducing hedging costs, relative to a market in which index traders are absent. Although $C^{a g g}$ and $I$ seem to explain some portion of variation in the mean and in the volatility of hedging costs, the underlying economics suggests that there is likely to be considerable measurement error associated with our hedging cost variables. In particular, $E_{T}\left(P_{T}\right)$ may be a noisy estimate of $E_{t}\left(P_{T}\right)$. Among other considerations, $E_{T}\left(P_{T}\right)$ will reflect information that is revealed between $t$ and $T$ (e.g., crop forecasts). To address the issue of measurement and estimation error and to better understand the role of CITs in futures markets, we formally model

\footnotetext{
16 Given the potential noisiness of $E_{t}\left(P^{T}\right)$, as a robustness check, we consider an alternative measure of hedging | cost: the daily hedging cost defined as $Y_{t+1, i, j}=\left(P_{t+1, i, j}-P_{t, i, j}\right) / P_{t, i, j}$, and re-estimate equations (1), (2), and (3). We also estimated a version of equation (1) where we substitute the default spread with the credit default swap spread for the North America investment grade index which is a function of the default probability. These robustness checks confirm the findings reported in Table 2 (see Supplemental Appendix).
} 
the market price for risk insurance in the next section, and derive implications for inter-month price spreads, as well as hedging costs. The advantage of analyzing inter-month spreads is that changes in market fundamentals will likely be reflected in the prices of all maturities of the commodities, and hence likely not have a large impact on price differences.

\section{The effect of CIT trading on pricing}

In this section, we present a model of equilibrium in futures markets in which CITs participate. The model incorporates several salient features of commodity markets. The first important feature is that contracts of different maturities trade simultaneously. At any point in time, eight or more contracts of different maturities are trading in each product. Second, hedgers are net long in the physical product, hence their hedging consists of short futures positions. Importantly, the hedgers' risk primarily pertains to price changes between the trade date and the date at which the harvested crop can be bought or sold. As shown below, this implies that most hedgers will take large short positions in the first post-harvest futures contract each year. ${ }^{17}$ The model enables us to characterize the impact of index trading on equilibrium prices.

\subsection{Empirical regularities}

Figure 2 presents some evidence in support of the premise that hedgers take particularly large positions in the post-harvest contract. It shows that during the eight plus years in our sample, the most important group of hedgers, distributors, have on average, established short positions of nearly 20,000 contracts in each year's December wheat contract by mid-March (270 days before expiration of the December contract), and retained positions of about that magnitude

\footnotetext{
17 For non-agricultural commodities, hedgers will take large short futures positions in maturities corresponding to when they are building up inventories. Consequently, the biggest short positions are in the contracts that expire just prior to demand peaks.
} 
until the December contract became the closest-to-maturity (nearby). In contrast, for other maturity months, their typical short positions are less than 5,000 contracts until the contract becomes the nearby. Similar patterns exist for corn and soybeans.

The other relevant institutional feature is that the leading CIT traders largely establish their trading positions independent of contemporaneous price. As Stoll and Whaley (2010) note, commodity index traders typically have simple buy-and-hold strategies, which allow them to take advantage of the diversification these assets provide. They term this commodity index investment, rather than trading, in order to emphasize the passive nature of their investment. As noted above, this is particularly true in agricultural markets. The two largest index funds (GSCI and DJ-UBS), which together represent about one-third of the CIT positions during our sample, announce their annual futures market trading decisions prior to the first trading day of the year. ${ }^{18}$ In particular, they announce the percentage of their assets that will be allocated to each futures contract, which maturities of those commodity contracts they will hold, and the dates they will move positions between maturities. The amount allocated to each commodity is proportional to its world production and/or futures market trading.

One common feature of CITs is that they primarily take positions in the nearby contract, which requires them to move their positions from the soon-to-expire nearby contract to the succeeding maturity contract. ${ }^{19}$ Panels A, B and C of Figure 3 show average CIT positions in the nearby and the first deferred contracts for the three commodities, as functions of the number of days until the nearby contract reaches its expiration. The three panels portray similar patterns; while CITs' overall positions do not vary much over the course of a contract lifecycle, their

\footnotetext{
${ }^{18}$ Index funds are a major subset of index traders. See Stoll and Whaley (2010) for a thorough description of the practical aspects of commodity index trading.

${ }_{19}$ In the last few years, some CITs have begun taking long positions in more distant contracts and holding them for longer, which requires less rolling between contracts.
} 
positions in individual maturities vary dramatically over this cycle. Specifically, for all three commodities, CITs' positions in the first deferred contract are small compared to their positions in the nearby contract at a point two months prior to expiration. Over the succeeding month or so, they move their positions from the nearby contract to the first deferred contract. Most of this roll takes place between 30 and 40 days prior to contract expiration.

CITs are like open-end index mutual funds, in that they represent individual and institutional investors, who are free to change their holdings of the index at any time. Hence, while the timing of CITs' roll is pre-announced, the amount of money invested in an index can vary. For this reason, changes in CIT positions can potentially represent information about fundamentals. We see the potential for the roll to contain such information to be minimal, however, for several reasons. First, even if investors have private information (i.e., information not yet incorporated into futures prices), it is unlikely that the investors would gain that information at a time coincident with the roll. Moreover to the extent that investors have private information about individual commodity prices, trading on that information would be more profitable if it were directed to the individual futures market, rather than to a bundle of commodities. ${ }^{20}$ For these reasons, we view CIT behavior during the roll as unlikely to reflect new information about fundamentals.

Of course, when CITs acquire a long position in a contract, there must be counterparties with corresponding short positions in that contract. Figure 4 displays the average positions of four groups of traders in the nearby corn contract, as it moves towards expiration. Market makers (floor brokers), hedge funds (managed money), and agricultural distributors (hedgers) hold positions that are in aggregate about the same size as CIT positions in the nearby contract.

\footnotetext{
20 Put somewhat differently, informed traders are likely to be firms involved in commercial activities in a commodity, a group that generally trades directly in futures markets. In contrast, investors who trade through CITs are generally institutions and individuals with no direct involvement in commodity markets.
} 
Market makers’ overall position looks quite different, however. Figure 5 shows the pattern of market maker positions in the wheat market. They hold long positions in deferred wheat contracts that are nearly equal in size to their short positions in the nearby contract. As we show below, this pattern is consistent with rational behavior by market makers, given the strategies of CITs and agricultural distributors (hedgers).

To summarize, as an empirical regularity, we see that CITs primarily take long positions in the nearby contract, and their counter-parties in that contract consist of distributors, market makers, and hedge funds. These latter two groups appear to hedge their short positions in the nearby by taking long positions in deferred contracts. CITs move positions from the nearby contract to the first deferred contract in a predictable manner, as the nearby moves towards expiration. Finally, hedgers take especially large short positions in the post-harvest contract each year.

\subsection{Modeling trader behavior}

To reflect these empirical regularities, we consider a model with two maturities of contracts in a single commodity each year, and three trader types; short hedgers (distributors), index traders (CIT), and speculators (corresponding to floor traders and managed money traders depicted in Figure 4). ${ }^{21}$ Each contract is the nearby for a $T$-day period, and we refer to period $i$ as the $T$ days in which maturity $i+1$ is the nearby. We characterize each kind of agent in a way that is broadly consistent with their observed trading patterns.

4.2.1. Index traders: To reflect the buy-and-hold strategy of their investments, we model index trader positions as exogenous; during the period in which contract $i$ is the nearby, CITs have an

\footnotetext{
21 Of course, CITs are speculators in a fundamental sense. We use the term speculator in the context of our model to refer to traders that both have no position in the underlying physical product, and take positions based on contemporaneous prices.
} 
initial long position of size $I_{i}$ in contract $i$, and roll into maturity $i+1$ over the course of the $T$-day period (consistent with the pattern shown in Figure 3). We let $\gamma$ denote the share of the CIT position remaining in the nearby contract (so that $\gamma=1$ at $t=0$ ).

4.2.2. Other traders: Other trader groups optimally allocate their portfolios, anticipating CIT behavior, and viewing the trading activity of CITs as not being information-based. Hence, we assume that hedgers and speculators take utility-maximizing positions in the various maturity futures contracts that are traded each day, and have identical knowledge of market fundamentals. Traders in these groups differ only in regard to their endowments; hedgers have positions in the underlying that essentially result in their being long in the physical commodity. Importantly, these "physical" positions cannot be sold at $t=0$ [very much in the spirit of Grossman and Miller, (1988)]. Specifically, we assume that hedgers (distributors) have cash market positions of size $C$ in the maturity $i=2$ contract (e.g., the current-year crop will be harvested sometime between the expiration of contract 1 and the expiration of contract 2). ${ }^{22}$ This leads to seasonality in hedging demand. A similar seasonality in hedging demand exists in many non-agricultural markets. For example, due to seasonality in product demand, natural gas distributors hold larger physical inventories in anticipation of increased sales (e.g., in fall and winter), and seek to hedge those inventories through futures markets positions.

\subsection{Equilibrium pricing}

In contrast to CITs, hedgers and speculators choose utility-maximizing positions, given prices. In this section, we solve for the positions of these traders, and the resultant prices. We

\footnotetext{
${ }^{22}$ In the two-period model presented here, it is appropriate to think of period 1 as a post-harvest contract (in which hedgers realize the value of their endowment at the end of the period), and period 0 as a pre-harvest period. In the Appendix, we generalize the model to have multiple pre-harvest periods each year, and multiple years. This allows us to examine how spreads vary over the harvest cycle.
} 
simplify the analysis by assuming that consumption only takes place in period 2 . We consider a two-period model; trading occurs at two dates, 0 and 1, in two tradable assets (contracts). The two assets are futures contracts on the same commodity, maturing at dates 1 and 2, respectively. The maturity 1 contract only trades on date 0 , while the maturity 2 contract trades on both date 0 and date 1. Figure 6 portrays the timing of events.

We can write an agent's utility as:

$$
U\left[W_{0}+X_{1}^{2}\left(P_{1}^{2}-P_{0}^{2}\right)+X_{2}^{2}\left(P_{2}^{2}-P_{1}^{2}\right)+X_{1}^{1}\left(P_{1}^{1}-P_{0}^{1}\right)+\left(P_{2}^{2}\right) C_{k}\right]
$$

where $P_{j}^{i}$ is the price of futures contract $i(i=[1,2])$ at time $j(j=[0,1,2]), X_{j}^{i}$. is the trader's position at time $j$ in the futures contract that matures at time $i, W_{0}$ is initial wealth, and $C_{k}$ is the trader's cash position in the underlying product ( $=C$ for hedgers, and 0 for speculators). That is, the agent consumes his entire period 2 wealth, which is equal to his initial wealth, plus the value of his position in the underlying as of $t=2$, plus or minus the gain/loss he or she makes on his or her futures trades.

To make the analysis tractable, we make the standard assumptions that the distribution of price changes is normal, and that each distributor and speculator has the same exponential utility functions of the form:

$$
U(W)=A-\exp \left(-\alpha W_{2}\right)
$$

In combination, these assumptions mean that each agent's utility function depends only on the mean and variance/covariances of the price change distributions.

To determine the optimal futures positions of these agents in periods 0 and 1 , we use backward induction. Solving for the period 1 optimum, we note that both speculators and hedgers choose $X_{2}^{2}$ to maximize (4), given the realizations of previous prices and previous 
choices of $X_{j}^{i}$, and their expectations about the mean and variance of the distribution of $P_{2}^{2}$. This leads to demand for futures positions equal to:

$$
X_{2, k}^{2}=\frac{E_{1}\left[P_{2}^{2}-P_{1}^{2}\right]}{\alpha\left(\sigma_{2}^{2}\right)^{2}}-C_{k}
$$

where $\sigma_{j d}^{i f}$ is the covariance between the time $j$ and $d$ changes in prices of maturities $i$ and $f$ (e.g., $\sigma_{12}^{12}$ is the covariance between changes in the period 1 price of maturity 1 and the period 2 price of maturity 2; when $j=d$ or $i=f$, we indicate the time/maturity with a single subscript/superscript; e.g., $\left(\sigma_{2}^{2}\right)^{2} \equiv\left(\sigma_{22}^{22}\right)^{2}$ is the variance of changes in $\left.P_{2}^{2}\right) .{ }^{23}$. In order for the market for maturity 2 to clear on date 1 , it must be the case that:

$$
N_{H} X_{2, H}^{2}+N_{S} X_{2, S}^{2}=-I_{2}
$$

where $I_{2}$ is index trader position at $t=1$, all of which is invested in contract 2, by construction; subscripts $H$ and $S$ refer to hedgers and speculators, respectively. Since $X_{2, S}^{2}=X_{2, H}^{2}+C$, we have $X_{2, H}^{2}=\frac{-\left(I_{2}+N_{S} C\right)}{N_{S}+N_{H}}$.

Finally, using equation (5), we find that:

$$
P_{1}^{2}=E_{1}\left(P_{2}^{2}\right)+\frac{\alpha\left(\sigma_{2}^{2}\right)^{2}}{N_{S}+N_{H}}\left(I_{2}-N_{H} C\right) .
$$

Turning to the optimization at $t=0$, given the choice of $X_{2, k}^{2}$, agents choose levels of $X_{1}^{2}$ and $X_{1}^{1}$ in order to maximize (4), given their expectations as of $t=0$, and their optimal decision at $t=1$ (i.e., equation (5)). The two first-order conditions at $t=0$ with respect to positions are:

$$
\begin{aligned}
& \left(\sigma_{1}^{1}\right)^{2} X_{1, k}^{1}+\sigma_{1}^{12} X_{1, k}^{2}=\frac{E_{0}\left[P_{1}^{1}-P_{0}^{1}\right]}{\alpha}-\sigma_{12}^{12}\left(X_{2, k}^{2}+C_{k}\right)+\sigma_{1}^{12}\left(X_{2 k}^{2}\right) \\
& \sigma_{1}^{12} X_{1, k}^{1}+\left(\sigma_{1}^{2}\right)^{2} X_{1, k}^{2}=\frac{E_{0}\left[P_{1}^{2}-P_{0}^{2}\right]}{\alpha}-\sigma_{12}^{2}\left(X_{2, k}^{2}+C_{k}\right)+\left(\sigma_{1}^{2}\right)^{2} X_{2, k}^{2} .
\end{aligned}
$$

${ }^{23}$ We model each trader as a price-taker with respect to market prices, so that each trader views the variances and covariances of price changes as exogenous to his or her trading decisions. 
As above, market clearing implies that:

$$
N_{H} X_{1, H}^{1}+N_{S} X_{1, S}^{1}=-\gamma I_{1}
$$

and

$$
N_{H} X_{1, H}^{2}+N_{S} X_{1, S}^{2}=-(1-\gamma) I_{1}
$$

where $\gamma$ is the percentage of total CIT holdings that is invested in the nearby maturity.

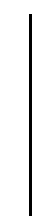

Using the relationship $X_{2, H}^{2}=X_{2, S}^{2}-C$, it follows from (7) and (8) that $X_{1, H}^{1}=X_{1, S}^{1}$, and $X_{1, H}^{2}=X_{1, S}^{2}-C$. Hence, we can express $X_{1, S}^{1}$ and $X_{1, S}^{2}$ in terms of the exogenous variables: $C$ (the hedgers' cash positions), commodity index traders' futures positions. and the variance/covariance matrix. We then use equations (7) and (8) to solve for the two equilibrium time 0 prices:

$$
\frac{E_{0}\left[P_{1}^{1}-P_{0}^{1}\right]}{\alpha}=\sigma_{12}^{12}\left(X_{2, H}^{2}+C\right)+\left(\sigma_{1}^{1}\right)^{2} X_{1, H}^{1}+\sigma_{1}^{12} X_{1, H}^{2}-\sigma_{1}^{12} X_{2, H}^{2}
$$

which yields the following price for the maturity 1 contract:

$$
P_{0}^{1}=E_{0}\left(P_{1}^{1}\right)-\alpha\left[\sigma_{12}^{12}\left(\frac{N_{H} C-I_{2}}{N_{S}+N_{H}}\right) R-\left(\sigma_{1}^{1}\right)^{2}\left(\frac{\left(\gamma I_{1}\right)}{N_{S}+N_{H}}\right)-\sigma_{1}^{12}\left(\frac{(1-\gamma) I_{1}+N_{S} C}{N_{S}+N_{H}}\right)+\sigma_{1}^{12}\left(\frac{I_{2}+N_{S} C}{N_{S}+N_{H}}\right) R\right]
$$

and

$$
\frac{E_{0}\left[P_{1}^{2}-P_{0}^{2}\right]}{\alpha}=\sigma_{12}^{2}\left(X_{2, H}^{2}+C\right)+\sigma_{1}^{12} X_{1, H}^{1}+\left(\sigma_{1}^{2}\right)^{2} X_{1, H}^{2}-\left(\sigma_{1}^{2}\right)^{2} X_{2, H}^{2}
$$

which yields the following price for the maturity 2 contract:

$$
P_{0}^{2}=E_{0}\left(P_{1}^{2}\right)-\alpha\left[\sigma_{12}^{2}\left(\frac{N_{H} C-I_{2}}{N_{S}+N_{H}}\right) R-\sigma_{1}^{12}\left(\frac{\left(\gamma I_{1}\right)}{N_{S}+N_{H}}\right)-\left(\sigma_{1}^{2}\right)^{2}\left(\frac{(1-\gamma) I_{1}+N_{S} C}{N_{S}+N_{H}}\right)+\left(\sigma_{1}^{2}\right)^{2}\left(\frac{I_{2}+N_{S} C}{N_{S}+N_{H}}\right) R\right]
$$

where $R=\left[N_{S}^{1} /\left(N_{S}^{1}+N_{H}^{1}\right)\right] /\left[N_{S}^{0} /\left(N_{S}^{0}+N_{H}^{0}\right)\right]$. 
This analysis characterizes equilibrium behavior and the implications for pricing at two trade dates: $t=0$ and $t=1$. More generally, if one were to imagine a series of dates during period 0 (i.e., prior to the expiration of contract 1), equations (7) and (8) represent equilibrium behavior on each of those dates. Similarly, equation (5) characterizes equilibrium behavior at every time between date 1 and date 2 (period 1). Of particular interest is the effect of CIT rolling during each period. That is, as depicted in Figure 3, during each period, CITs generally move their positions from the nearby contract (i.e., contract 1 in period 0 ) to the first-deferred contract (i.e., contract 2 in period 0). As shown below, our model yields testable implications for prices and spreads associated with those changes in positions. In this sense, equations (9) and (10) characterize the cost of hedging using contracts 1 and 2, respectively, for every $t$ in period 0 . These equations formalize the premise that hedging costs are increasing in $C$ and decreasing in $I$. It also suggests that, roughly speaking, whether traders can make positive expected returns by holding contract 1 to maturity (normal backwardation) depends on the relative sizes of $C$ and $I$. That is, the price of insurance is likely to be positive if the size of the cash market position of traders seeking to hedge $(C)$ is large relative to positions of traders seeking exposure to futures price variability (I). Equations (9) and (10) also formalize the proposition that the price of hedging is increasing in the covariance between the returns of hedgers' endowed position and the futures contract. ${ }^{24}$

Note that we predict that speculators will take calendar spread positions. Specifically, they will be short in the nearby contract and long in other maturity contracts whenever CITs are primarily invested in the nearby contract (i.e., when the percentage of their positions, $\gamma$, is greater

\footnotetext{
24 Hirshleifer (1988) finds this same result in a model in which there is only one futures contract, but speculators can hold assets in other asset classes.
} 
than 0.5). ${ }^{25}$ As CITs move their positions into the first deferred contract, speculators will likewise take a larger short (or smaller long) position in the first deferred contract. We also predict that hedgers will have a larger position in the nearby contract in the post-harvest contract than the pre-harvest contract (i.e., $\left|X_{2}^{2}\right|>\left|X_{1}^{1}\right|$ ). Another implication is that changes in the size of CIT aggregate holdings can affect prices of futures contracts, even prior to CITs having positions in that contract. In particular, equation (10) implies that the initial price of the first deferred contract is affected by CITs' aggregate position at $t=0$, even though CITs have no position in the deferred at that time. The intuition is that the size of CITs' positions will affect the price of the deferred at $t=1$, which changes the expected price of the deferred and hence the demand of speculators and hedgers at $t=0$. In this sense, traders anticipate future CIT behavior, and the initial price adjusts to reflect that. It follows that the price of the deferred contract at $t=0$ would be lower in the absence of CITs.

These predictions are consistent with observed trading patterns (see Figures 2 and 5). As shown in Figure 4, the position of speculators is the mirror image of CIT positions in the nearby contract, especially between 60 and 15 days prior to expiration. However, their positions aggregated across all maturities are quite different; the net positions of speculators, aggregated across all maturities, is much closer to zero, and changes very little as the nearby reaches maturity. These patterns suggest that speculators are serving as counter-parties to CITs in the nearby contract, and to hedgers in more distant maturities.

In the Appendix, we generalize the model to develop additional testable implications. First, we consider a model with multiple pre-harvest periods. This allows us to evaluate how prices change over each production cycle. It also allows us to distinguish between the effects of a CIT's announcement of its future trades, and the actual trading. One implication of that analysis | ${ }^{25}$ For example, if $\gamma=0$ in period 1 , then $X_{1, S}^{2}>0$, and $X_{1, S}^{1}<0$. 
is that there is a price effect of a CIT's trading, both at the time of announcement and at the time of execution. Second, we consider a model in which hedgers have an endowment in both periods, and consume in multiple periods, which corresponds to an environment in which hedgers have periodic (e.g., annual) harvests. This enables us to generate implications for prices in the postharvest periods.

Overall, we can use our model to explain many of the patterns of traders' behavior. The model is also predictive of futures prices. In the next section, we develop some testable implications for price differences between maturities. We focus on price differences, because price levels will largely reflect demand and supply fundamentals; whereas changes in these fundamentals likely affect all prices similarly, so that differences are more likely to reflect the factors in our model.

\subsection{Comparative statics}

Because CITs primarily take positions in only one or two maturities at any given time, to the extent that CIT trading affects futures prices, it will affect different maturities differentially. Thus, one might expect the intermonth spread to vary predictably with CIT behavior.

Specifically, we next consider how $S_{0}$ (the intermonth spread) $\equiv t P_{0}^{2}-P_{0}^{1}$ varies over a period. Using equations (9) and (10), we have the following comparative static :

$$
\frac{\partial S_{0}}{\partial \gamma}=\frac{\alpha I}{N_{H}+N_{S}}\left[2\left(\sigma_{1}^{12}-\left(\sigma_{1}^{1}\right)^{2}-\left(\sigma_{1}^{2}\right)^{2}\right]<0 .\right.
$$

That is, as index traders (in aggregate) roll their positions from maturity 1 contract to maturity 2 contract $(\gamma$ falls), the spread between the futures prices of contract 2 and contract 1 rises. This is to be expected, since there is a selling pressure on the maturity 1 contract and a buying pressure 
on the maturity 2 contract. Spreads will also vary with the aggregate size of CIT positions at $t=$ 0 :

$$
\frac{\partial S_{0}}{\partial I_{1}}=\frac{\alpha}{N_{H}+N_{S}}\left[(2 \gamma-1) \sigma_{1}^{12}-\gamma\left(\sigma_{1}^{1}\right)^{2}+(1-\gamma)\left(\sigma_{1}^{2}\right)^{2}\right] .
$$

The sign of this expression varies with $\gamma$; it is positive for $\gamma=0$ and negative for $\gamma=1$. The logic is that when $\gamma=0$, CITs only have positions in maturity 2, and the larger their positions, the higher is $P_{0}^{2}$, while $P_{0}^{1}$ is unaffected (and conversely when $\gamma=1$ ). More generally,

$$
\frac{\partial S_{0}^{2}}{\partial \gamma \partial I}=\frac{\alpha}{N_{H}+N_{S}}\left[2 \sigma_{12}^{2}-\sigma_{1}^{2}-\sigma_{2}^{2}\right]<0
$$

so that the larger the size of the position being rolled, the more rapidly the spread increases with the percentage of their holdings in the first deferred contract.

Finally, changes in the hedgers' cash positions, $C$, will tend to have a negative effect on the spread:

$$
\frac{\partial S_{0}}{\partial C}=\frac{1}{N_{H}+N_{S}}\left[N_{S}(R-1)\left(\sigma_{1}^{12}-\left(\sigma_{1}^{2}\right)^{2}+N_{H}\left(\sigma_{12}^{12}-\sigma_{12}^{2}\right)\right]\right.
$$

This is negative as long as $R \geq 1$ and $\sigma_{12}^{2}>\sigma_{12}^{12}$, i.e., $P_{0}^{2}$ is more closely correlated with $P_{1}^{2}$ than is $P_{0}^{1}$. The latter condition seems reasonable, since we would expect the correlation between movements in period 1 and period 2 futures prices to be higher between the same maturity than adjacent maturities.

As shown in the Appendix, this conclusion regarding the relationship between $C$ and the spread depends on where in the harvest cycle one evaluates the spread. The analysis in the Appendix shows that the effect of $C$ on the spread is more likely to be negative later in the harvest cycle (because the correlation between the price change for the nearby maturity and the endowment is higher), and will be unambiguously positive during the post-harvest period. 
Another implication of the model is that the price of hedging, which is really the reciprocal of the return to holding a long position, should be correlated across commodities, at least those commodities within the typical fund's holdings. That is, since index funds tend to hold a fixed portion of their portfolios in each of many commodities, changes in CIT positions will be highly correlated across the commodities CITs buy and hold. Since changes in CIT positions will change futures returns in the same direction for all of these commodities, we would anticipate that the presence of CITs should increase the correlation of futures returns across contracts in which they take positions, even those unrelated in demand and supply. Indeed, Tang and Xiong (2012) find that the correlations of returns for contracts for which CITs take positions are higher than those for contracts in which CITs do not invest.

\section{Empirical implementation and results}

The model outlined in Section 3 yields predictions about the relationship between prices and trader positions (specifically, $I$ and $C$ ). Because we have daily observations on CIT and hedger positions in each maturity, we can directly test these hypotheses. We measure prices by the daily closing (settlement) prices on the Chicago Board of Trade. As discussed above, price levels are more likely affected by changes in fundamentals than are price differences. Hence, the primary variable of interest in testing our model is the difference between the daily settlement prices of the first deferred contract and the nearby contract, which we refer to as the spread. ${ }^{26}$

\footnotetext{
${ }^{26}$ For soy, the definition of the first-deferred contract and the nearby contract is somewhat ambiguous, in that while there are seven contract maturities each year, only five of these have significant volume. In particular, CITs rarely trade the August and September soybean contracts; generally they roll their positions from the July contract to the November contract. In the results below, we consider the November contract as the first-deferred when the July is the nearby, and treat it as the nearby from mid-July through its expiration. We have, however, checked the robustness of our results to defining the spread as the difference between the August and July maturities when July is the nearby; our results are unaffected.
} 
The trader position variables are constructed from the daily position data in the CFTC LTRS database. The empirical counterpart of $I$ is the maximum observed end-of-day position of CITs in each maturity contract. The maximum is typically reached 50-60 days before contract expiration. $\gamma$ is the ratio of the end of day CIT position in the nearby contract to $I$. The empirical counterpart of $N_{k}$, the number of traders in category $k$ for each maturity, is the maximum observed number of traders in category $k$ for each maturity. ${ }^{27}$

In the model, $C$ represents the physical quantity that hedgers will possess at some future date in the current year. As such, in the agricultural context, it is most appropriate to think of $C$ as the post-harvest, cash market long positions of these traders. Although the commercial traders in several of the LTRS categories are net short hedgers, we focus on the futures positions of the largest such category, agricultural distributors. These traders are particularly relevant to our analysis, not only because they represent the largest category of commercial trader, but also because as a group, they are consistently short in the futures market - both over time and between commodities. $^{28}$

As a result, our estimates of $C$ are based on the observable futures positions of agricultural distributors, which by (7) and (8), bears a relationship to C. Specifically, market clearing at $t=0$ (i.e., the pre-harvest period) ${ }^{29}$ implies that:

$$
C=-\frac{\left(N_{H}+N_{S}\right) X_{1, H}^{2}+(1-\gamma) I_{1}}{N_{S}}
$$

\footnotetext{
${ }^{27}$ We take the maximum number under the logic that all of those traders could potentially trade on any given day, which corresponds to the notion of $N_{k}$ in the model.

${ }^{28}$ To be sure, there are many traders in other categories who behave similarly to the distributors. However, we choose not to reclassify traders into categories based on our perception of that trading, preferring instead to use the existing classifications established by the CFTC.

${ }^{29}$ As shown in the Appendix, with more than two maturities per harvest cycle, the expression for $C$ is only correct for the final pre-harvest maturity contract. The corresponding expression for other pre-harvest maturities is similar, save that the $(1-\gamma) I_{1}$ term is not present.
} 
As Figure 2 indicates, hedgers begin to establish a futures position in the following year's post-harvest contract during the period in which the current year's post-harvest contract is the nearby. This suggests that hedgers begin accumulating positions in the following year's physical product (i.e., through planting and forward contracts) during the period in which this year's physical product is obtained. In the Appendix, we evaluate a more general model in which hedgers have physical positions in multiple periods. This enables us to derive expressions for both current and next year's physical positions. The model implies that during post-harvest period, $t$, the two relevant cash positions are:

$$
C_{t}^{c u r r}=-\frac{\gamma I_{t}+\left(N_{S}+N_{H}\right) X_{t, H}^{t}}{N_{S}},
$$

while

$$
C_{t}^{n e x t}=-\frac{\left(N_{S}+N_{H}\right) X_{t, H}^{t+\tau}}{N_{S}}
$$

where $\tau$ is the number of periods each year.

It is important to note that we do not observe $C^{\text {curr }}$ or $C^{\text {next }}$ directly. The above relationships are derived from the model and we use them to approximate the hedgers' cash positions. Hence, our tests of the effect of $C$ on spreads derive directly from the model.

In addition to CIT and hedger (distributor) positions, we anticipate that spreads would also be affected by the period of time until expiration of the nearby contract, $\Lambda$, which also accounts for seasonality in the data. Finally, we would also like to test whether, holding the level of positions constant, the rate of change in CIT positions in the nearby (the roll) affects spreads. We measure the roll as the absolute value of the daily change in CIT positions in the nearby contract.

Before describing the details of how we test the model's predictions, we provide some discussion of the data. 


\subsection{Summary statistics}

Our data cover the period July 2003 through November 2012 and refer to daily observations. Table 3 reports descriptive statistics of the data; corn in panel A, soy in panel B, and wheat in panel C. The three products are similar in most respects. For example, our tests show that none of the variables have Gaussian distributions, although all are stationary. Average calendar spreads are positive for all three products, indicating that the term structure of futures prices is typically upward sloping in our sample. All three spreads are also highly autocorrelated. Soybean calendar spreads are much more volatile than the other two products.

As discussed above, a key determinant of hedging costs is the relative size of I, CITs' long futures market position, and $C_{t}^{a g g}=C_{t}^{c u r r}+C_{t}^{\text {next }}$, the physical (cash) positions held by hedgers. These two variables are of similar magnitude for soy, but $I$ is more than twice as large as $C_{t}^{a g g}$ for wheat, which implies that CITs are meeting the demand of hedgers other than distributors, while it is less than half of $C_{t}^{a g g}$ for corn, ${ }^{30}$ which implies that demand for hedging is much higher than the CITs' long positions. We also note that $C_{t}^{a g g}$ is more volatile than $I$ for these three commodities. $I$ and $C_{t}^{a g g}$ are highly autocorrelated.

The mean of $\gamma$ is just above 0.5 for all three products, indicating that, on average, CITs hold slightly more than half of their positions in the nearby contract. This indicates that the roll occurs roughly symmetrically around the middle of the period in which each maturity of each contract is the nearby. Finally, the last column of Table 4 reports summary statistics for the ratio of $C_{t}^{\text {curr }}$ to $C_{t}^{a g g}$, which represents the percentage of total hedger cash position in the current

${ }^{30}$ Note that the estimate of $C_{t}^{c u r r}$ here is based on distributor (hedger) positions only. As shown in Table 1, there is short hedging by traders in other categories, especially for soybeans and wheat. As such, total $C_{t}^{c u r r}$ may be significantly larger than indicated by Table 3. Nevertheless, since distributors constitute the largest portion of these traders, the estimation should reflect the bulk of the changes in $C_{t}^{c u r r}$. 
year crop during the post-harvest period (when the November contract is the nearby in soy and the December contract is the nearby in corn and wheat). It averages between 0.7 and 0.9 for the three products. That is, $10 \%-30 \%$ of hedger cash positions are in the following year's harvest before the current year's post-harvest contract reaches expiration.

The following section uses this data to test some of the predictions we generate from our model.

\subsection{Testing the predictions}

The spread exhibits serial correlation and heteroscedasticity. To mitigate the effect of these factors and to fully capture the dynamics of both the conditional mean and the conditional variance, we adopt the GARCH(1,1) specification, which is very flexible and widely used for describing the evolution of financial variables. ${ }^{31}$ More specifically, we estimate GARCH models with variance targeting (where the unconditional variance of the GARCH model is restricted to be equal to the sample unconditional variance). Francq, Horvath, and Zakoïan (2011) show that when the model is misspecified, GARCH estimates with variance targeting are superior to unrestricted GARCH estimates. ${ }^{32}$ We estimate the following model for the spread for each commodity $j$ :

$$
\begin{gathered}
S_{t, j}=\theta_{0, j}+\theta_{1, j} I_{t, j}+\theta_{2, j} \gamma_{t, j}+\theta_{3, j} \gamma_{t, j} I_{t, j}+\theta_{4, j} C_{t, j}^{c u r r}+\theta_{5, j} C_{t, j}^{c u r r} D_{t, j}^{\text {pre-harv }} \\
+\theta_{6, j} C_{t, j}^{c u r r} D_{t, j}^{\text {post-harv }}+\theta_{7, j} \Lambda_{t, j}+\theta_{8, j} \text { Roll }_{t, j}+\theta_{9, j} C_{t, j}^{\text {next }} D_{t, j}^{\text {post-harv }}+\varepsilon_{t, j} \\
\varepsilon_{t, j}=\sqrt{h_{t, j}} u_{t j i} \\
h_{t, j}=\omega_{0, j}+\omega_{1, j} h_{t-1, j}+\omega_{2, j} \varepsilon_{t-1, j}^{2}+\omega_{3, j} \Lambda_{t, j}
\end{gathered}
$$

31 Hansen and Lunde (2005) compare over 300 volatility models and show that the GARCH(1,1) model well describes and well predicts the conditional variance of financial assets.

32 In our empirical application, we employ both the unrestricted GARCH model and the variance targeting GARCH and found the latter better describes the data in terms of likelihood ratio tests, Akaike and Schwartz information criteria. 
where $u_{t, j}$ is a sequence of independent and identically distributed (i.i.d.) random variables such that $E\left(u_{t, j}^{2}\right)=1 ; D_{t, j}^{\text {pre-harv }}$ is a dummy variable, which is equal to 1 when the pre-harvest is the

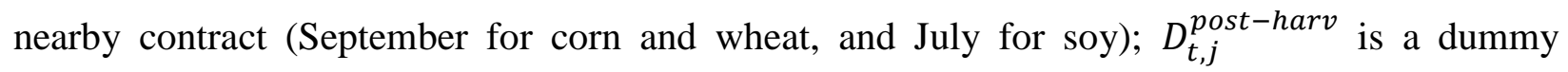
variable equal to 1 when the post-harvest is the nearby contract (December for corn and wheat, and November for soy). In the conditional variance equation $\left(h_{t, j}\right)$, we add an additional term equal to the number of days until expiration $\left(\Lambda_{t, j}\right)$ to account for the time pattern of prices as contracts move towards expiration. ${ }^{33}$

The estimation technique requires us to choose a distribution for $u_{t, j}$. Most GARCH models are estimated using a normal distribution. Unfortunately, the spreads here are highly nonnormal with negative skewness and high kurtosis. The markets we analyze are characterized by spreads that are positive almost all the time (the spread is negative only $7 \%$ of the time for corn, $19 \%$ for soy, and $1 \%$ for wheat). We, therefore, chose the generalized error distribution, which was introduced in the GARCH literature by Nelson (1991), since it accommodates the behavior of the spread in the tails. ${ }^{34}$

The theoretical model in the previous section allows us to make a number of predictions about the parameter values. Our goal is to test these predictions using the (reduced form) representation in equation (11). One prediction is that $\frac{\partial S}{\partial I}>0$ for $\gamma=0$ and $\frac{\partial S}{\partial I}<0$ for $\gamma=1$. In terms of equation (11), this implies that $\theta_{1}>0$, and $\theta_{3}<0$, such that $\theta_{1}+\theta_{3}<0$. Moreover, we predict a negative value on the coefficient of hedger cash positions $\left(\theta_{4}\right)$ for months in which the post-harvest contract is neither the nearby or the first deferred. When the last pre-harvest contract

${ }^{33} D_{t, j}^{\text {pre-harv }}, D_{t, j}^{\text {post-harv }}$, and $\Lambda_{t, j}$ also account for seasonality in the data.

${ }^{34} \mathrm{We}$ also employ a Student $t$-distribution where we estimate the degrees of freedom. However, standard test statistics show that the generalized error distribution fits the data better than the $t$-distribution. The results are nevertheless quite similar. 
is the nearby, we expect a larger (in absolute value) negative value for the coefficient on $C_{t}^{\text {curr }}$, so that $\theta_{5}<0$. For the post-harvest contract, we expect $\frac{\partial S}{\partial C^{c u r r}}>0$, so that $\theta_{6}>0$ and $\theta_{6}+\theta_{4}>0$. Conversely, in the post-harvest period, we expect $\frac{\partial S}{\partial C^{\text {next }}}<0$, so that $\theta_{9}<0$. These predictions are summarized in Table 4, while Table 5, Panel A reports estimation results.

For all commodities, the signs of the estimated parameters in the Table 5, Panel A are generally in line with our predictions as depicted in Table 4, and are statistically significant. For example, the negative signs on $\theta_{2}$ in the three regressions mean that the spread increases as CITs move their positions from the nearby to the first deferred. ${ }^{35}$ Similarly, the negative signs on $\theta_{4}$ and $\theta_{9}$ (which are essentially our estimates of the effect of cash positions) and the positive sign on $\theta_{6}$ mean that the greater the extent to which hedgers seek to buy insurance (hedge their risks), the higher is the price they have to pay. The negative sign on $\theta_{5}$ indicates that, consistent with the model, this effect is (absolutely) larger when the last pre-harvest contract is the nearby, since the correlations between the nearby futures contract and the hedgers' underlying positions are higher. In combination, these findings indicate that futures prices are affected by the sizes of hedger and CIT positions, as implied by the model and the results in Table 2. To get an idea of the magnitude of these effects, we note that a one standard deviation increase in the current-year cash position of hedgers (distributors) in corn leads to a decrease in the spread of about 5 cents if the nearby is the January, March, or May contracts, and about twice that if the nearby is the July

\footnotetext{
35 Stoll and Whaley (2010) calculate the change in spread between the beginning and end of the primary rolling period for the largest CITs. They find that the elasticity of the spread with respect to the change in CIT position in the nearby is about 0.0033 for wheat, 0.0066 for corn, and -0.009 for soy (see Table II-3 of their paper). Our findings indicate larger elasticities, in the range of $0.09-1.39$, for the January-May contracts (calculated as $\mid \frac{\gamma}{s}\left(\theta_{2}+\theta_{3} I\right)$, where all variables are evaluated at their mean). A related finding, due to Mou (2010), is that spreads are higher during the period in which the largest CIT rolls its position than prior to the roll. Unlike these authors, we have daily data on CIT and hedger positions, which enables us to estimate specific relationships; for example, the relationship between day-to-day changes in CIT positions and the associated price changes. It also allows us to test specific predictions, such as the prediction that the effect of CIT positions on the spread will change with the harvest cycle.
} 
contract. It should be noted, however, that the effects of CITs on futures prices are temporary, in the sense that the futures price on the final trading day of a contract (and indeed any day after all rolling is complete) will not be affected by CIT behavior. Overall, the pattern of coefficients suggests the model correctly interprets market behaviors.

Our model implies that the level of CIT positions in individual maturities should affect the price of that maturity, and that trading activity on a trading day (i.e., the change in position) would only affect prices if they introduced new information. As noted above, the roll-over strategies of major CITs are announced well in advance and are unlikely to introduce any additional information to the market. Hence, we would expect $\theta_{8}$, the coefficient of Roll $_{t}$, not to be statistically significant. For both soy and wheat, however, rolling activity appears to increase the spread; the greater the daily increase in CITs' positions in the first deferred contract, the bigger is the spread. As such, the data indicates that trading activity affects prices in these two markets. One possible explanation of this finding is that some of the roll may not be completely predictable (i.e., the roll by CITs other than the major funds). This effect may be exacerbated in less liquid markets, which could explain why the effects are more significant in wheat and soybeans than in corn (which is the most liquid of the three).

There are also two cross-parameter restrictions implied by the theory: $\theta_{1}+\theta_{3}<0$ and $\theta_{4}+\theta_{6}>0$. As shown in Table 5, Panel C, we fail to reject the latter restriction at the $5 \%$ significance level for all three products. That is, the evidence supports the model's premise that when the first post-harvest contract is the nearby, the spread (that is, the price of the second postharvest contract minus the price of the first post-harvest contract) increases with the size of hedger positions in the current-year crop, contrary to the relationship when other contracts are the nearby. The evidence is less favorable for the first restriction. 
As shown in Table 5, Panel C, the conditional variance equation is well-specified and stable with the sum of $\omega_{1}$ and $\omega_{2}$ less than unity for all three commodities. The parameter $\omega_{3}$ is significant, indicating that there is seasonality in the second moment due to the life cycle of futures contracts. Although $\omega_{3}$ is negative, the conditional variance is always positive. In line with the summary statistics in Table 3, the GED parameter is less than 2 for all commodities, implying that the spread has fat tails. Finally the $\mathrm{R}^{2}$ indicates that the model well describes the evolution of the spread. This is particularly true for corn. Perhaps the lower $\mathrm{R}^{2}$ for soybeans reflects the fact that soy traders have a broader set of instruments to use for hedging their risk, since futures and options markets also exist for soy meal and soy oil. ${ }^{36}$

\section{Conclusion}

In this paper, we analyze the role of index traders in financial markets. Our perspective is that CITs serve as the low-cost providers of hedging to traditional short-side hedgers. That is, the prices that would have resulted from the trading of hedgers and traditional speculators alone allowed index traders to profitably take long futures positions. Consistent with this premise, we find that hedging costs fall as CITs positions grow. Alternatively, this finding can be viewed in terms of futures prices; CITs temporarily increase futures prices in specific maturities when they take long positions in that maturity.

Within this overall framework, there appears to be additional opportunities for profitable trading due to the temporal mismatch between the contract maturities in which CITs take long positions, and the maturities in which hedgers take short positions. The evidence suggests that

\footnotetext{
36 This may explain why agricultural distributors represent a much smaller percentage of open interest for soybeans than for the other two products. Some evidence of the use of such cross-hedging can be found in Brunetti and Reiffen (2014).
} 
other market participants are able to profitably accommodate both of these groups by taking spread positions (e.g., short in the nearby contract, long in deferred contracts).

We show that a sizable portion of the inter-month spread can be explained by the sizes of the positions of CITs and hedgers. In particular, consistent with our theoretical model, increases in the size of hedgers' cash positions lead to lower spreads (at least in the early portions of the harvest cycle). This reflects the idea that the price of assets that are highly correlated with hedgers' cash market positions more closely track changes in those positions. In addition, we find that CITs relative positions in different maturities affect the relative prices of those maturities in predictable ways. In particular, the price spread between the first deferred contract and the nearby contract increases as CITs move their positions from the nearby to the first deferred. As such, our findings show that our model can be used to understand important aspects of the trading behavior of various agents in the market, and how their trading has reacted to changes in the size of CIT positions in futures markets.

Underlying the premise of our model is the more general notion that traders are only willing to take on additional risk in exchange for higher compensation. By tracking the behavior of groups of similarly-situated traders, we document that traders behave consistent with models of finite liquidity. That is, it appears that observed price effects from changes in demand and supply for insurance against price risk can be explained by the higher cost (in terms of portfolio risk) incurred by speculators. This in turn implies that observed changes in spreads are not necessarily opportunities for arbitrage profits. 


\section{References}

Acharya, V., Lochstoer, L., Ramadorai, T., 2013. Limits to arbitrage and hedging: evidence from commodity markets. Journal of Financial Economics 109, 441-465.

Bessembinder, H., 1992, Systematic risk, hedging pressure, and risk premiums in futures markets. Review of Financial Studies 5, 637-667.

Brunetti, C., and Reiffen, D., 2014. Does hedging activity reflect cash market positions? Evidence from agricultural markets. Working Paper, US Federal Reserve.

Büyükşahin, B., Haigh, M., Harris, J., Overdahl, J., Robe, M., 2009. Fundamentals, trading activity and derivative pricing. Working Paper, American University.

Cheng, I-H., Kirilenko A., Xiong, W., 2012. Endogenous risk and the seismology of commodity futures markets. Working Paper, Princeton University.

Commodity Futures Trading Commission, 2006a. Comprehensive review of the commitment of traders reporting program. Federal Register 71, FR 35267.

2006b. Commission actions in response to the 'Comprehensive review of the commitments of traders reporting program. Washington, DC.

2008. Staff Report on Commodity Swap Dealers \& Index Traders with Commission Recommendations. Washington, DC.

de Roon, F., Nijman, T., Veld, C., 2000. Hedging pressure effects in futures markets. Journal of Finance 55, 1437-1456.

Dewally, M., Ederington, L., and Fernando, C., 2010. Determinants of Trading Profits of Individual Traders: Risk Premia or Information. Working Paper, University of Oklahoma.

Dhillon, U., Johnson, H., 1991. Changes in the Standard and Poor's 500 list. Journal of Business 64, 75-85.

Etula, E., 2013. Broker-dealer risk appetite and commodity returns. Journal of Financial Econometrics 11, 486-521.

Fama, E., French, K., 1989. Business Conditions and Expected Returns on Stocks and Bonds. Journal of Financial Economics 25, 23 - 49.

Fishe, R. Smith, A., 2012. Identifying informed traders in futures markets. Journal of Financial Markets 15, 329-359.

Francq, C., Horvath, L., Zakoïan, J-M., 2011. Merits and drawbacks of variance targeting in GARCH models. Journal of Financial Econometrics 9, 619-656. 
Garman, M., Klass, M., 1980. On the estimation of security price volatilities from historical data. Journal of Business, 53, 67-78.

Gorton, G., Hayashi, F., Rouwenhorst, G., 2012. The fundamentals of commodity futures returns. Review of Finance, 17: 35-105.

Greenwood, R., 2005. Short- and long-term demand curves for stocks: Theory and evidence on the dynamics of arbitrage. Journal of Financial Economics 75, 607-649.

Grossman, S., Miller, M., 1988. Liquidity and market structure. Journal of Finance 43, 617-633.

Hansen, P., and Lunde, A., 2005. A forecast comparison of volatility models: Does anything beat a GARCH(1,1)? Journal of Applied Econometrics 20, 873-889.

Harris, L., and Gurel, E., 1986. Price and volume effects associated with changes in the S\&P 500 list: New evidence for the existence of price pressures. Journal of Finance 41, 815-29.

Hartzmark, M., 1987. Returns to individual traders of futures: Aggregate results. Journal of Political Economy 95, 1292-1306.

Hicks, J., 1946. Value and Capital: An Inquiry into Some Fundamental Principles of Economic Theory ( $2^{\text {nd }}$ ed). ClarendonPress, Oxford.

Hirshleifer, D., 1988. Residual risk, trading costs, and commodity futures risk premia. Review of Financial Studies, 1, 173-193.

1990. Hedging pressure and futures price movements in a general equilibrium model. Econometrica 58, 411-428.

Jagannathan, R., and Wang, Z., 1996. The conditional CAPM and the cross-section of expected returns. Journal of Finance 51, 3-53.

Jain, P., 1987. The effect on stock price of inclusion in or exclusion from the S \& P 500. Financial Analysts Journal 43, 58-65.

Irwin, S. , and Sanders, D., 2010. The financialization of commodity futures markets or: How I learned to stop worrying and love index funds. Working Paper, University of Illinois.

Keynes, J., 1930. A Treatise on Money, Vol. 2. MacMillan \& Co, London.

Lux, T., 1995. Herd behaviour, bubbles and crashes. The Economic Journal 105, 881-896.

Masters, M., 2008. Testimony Before Senate Committee on Homeland Security and Governmental Affairs. May 20 2008. 
Mou, Y., 2010. Limits to arbitrage and commodity index investment: front-running the Goldman roll. Working Paper, New York University.

Nelson, D., 1991. Conditional heteroscedasticity in asset returns: A new approach. Econometrica 59, 347-370.

Shiller, R., 2003. From efficient markets theory to behavioral finance. Journal of Economic Perspectives 17, 83-104.

Shleifer, A., 1986. Do demand curves for stocks slope down? Journal of Finance 41, 579- 90.

Singleton, K., 2014. Investor flows and the 2008 boom/bust in oil prices. Management Science 60, 300-318.

Shleifer, A., and Summers, L., 1990. The noise trader approach to finance. Journal of Economic Perspectives 4, 19-33.

Stoll, H., and Whaley, R., 2010. Commodity index investing and commodity futures prices. Journal of Applied Finance 20, 7-46.

Tang, K., and Xiong, W., 2012. Index investment and financialization of commodities. Financial Analysts Journal 68, 54-74.

Varian, H., 2005. Bootstrap tutorial. Mathematica Journal 9, 768-775. 


\section{Table 1}

Large trader reporting system - average participation rate by category

\begin{tabular}{|c|c|c|c|c|c|c|}
\hline \multirow[b]{2}{*}{ Categories of Traders } & \multicolumn{2}{|c|}{ Corn } & \multicolumn{2}{|c|}{ Soy } & \multicolumn{2}{|c|}{ Wheat } \\
\hline & $\begin{array}{c}\text { Ave. \# of } \\
\text { traders }\end{array}$ & $\begin{array}{c}\text { Ave. share of } \\
\text { open interest } \\
\text { (\%) }\end{array}$ & $\begin{array}{l}\text { Ave. \# of } \\
\text { traders }\end{array}$ & $\begin{array}{c}\text { Ave. share of } \\
\text { open interest } \\
(\%)\end{array}$ & $\begin{array}{c}\text { Ave. \# of } \\
\text { traders }\end{array}$ & $\begin{array}{c}\text { Ave. share of } \\
\text { open interest } \\
\text { (\%) }\end{array}$ \\
\hline \multicolumn{7}{|l|}{ Commercial } \\
\hline Ag. distributors (AD) & 263.4 & -29.64 & 122.25 & -29.76 & 62.07 & -26.48 \\
\hline Ag. manufacturers (AM) & 48.34 & 3.14 & 19.22 & -0.72 & 15.46 & -2.73 \\
\hline Ag. - other (AO) & 20.96 & 0.41 & 10.03 & -1.10 & 6.37 & -0.31 \\
\hline Ag. producers (AP) & 23.42 & 0.52 & 10.03 & -0.44 & 6.74 & -0.52 \\
\hline Swap dealers (AS) & 12.02 & -0.28 & 6.84 & -0.58 & 13.93 & -1.28 \\
\hline \multicolumn{7}{|l|}{ Non-commercial } \\
\hline Floor traders (FBT) & 82.46 & -0.25 & 86.60 & -0.26 & 46.14 & -0.91 \\
\hline Managed money (MMT) & 110.10 & 3.22 & 89.76 & 5.27 & 72.20 & -2.86 \\
\hline Other managed money (NRP) & 19.36 & 0.06 & 12.2 & -0.17 & 13.04 & -0.32 \\
\hline Index traders (CIT) & 30.25 & 23.9 & 23.91 & 26.84 & 26.25 & 42.47 \\
\hline
\end{tabular}

Note: MMT and NRP are hedge funds. The data period covers July 2003 - November 2012. 
Table 2

Hedging costs

\begin{tabular}{|c|c|c|c|c|c|c|}
\hline & \multicolumn{2}{|c|}{ Corn } & \multicolumn{2}{|c|}{ Soy } & \multicolumn{2}{|c|}{ Wheat } \\
\hline & Hedging cost & $\begin{array}{l}\text { Volatility of } \\
\text { hedging cost }\end{array}$ & $\begin{array}{c}\text { Hedging } \\
\text { cost }\end{array}$ & $\begin{array}{l}\text { Volatility of } \\
\text { hedging cost }\end{array}$ & $\begin{array}{l}\text { Hedging } \\
\text { cost }\end{array}$ & $\begin{array}{l}\text { Volatility of } \\
\text { hedging cost }\end{array}$ \\
\hline $\begin{array}{l}\text { Dependent } \\
\text { variable mean } \\
\text { (basis points) }\end{array}$ & 2.5950 & 1.9243 & 10.539 & 1.6115 & 4.5136 & 1.9717 \\
\hline Constant & $\begin{array}{c}0.0802 \\
(0.1371)\end{array}$ & $\begin{array}{c}0.0162 * * * \\
(0.0022)\end{array}$ & $\begin{array}{c}0.1855 \\
(0.2748)\end{array}$ & $\begin{array}{c}0.0183^{* * *} \\
(0.0027)\end{array}$ & $\begin{array}{c}0.0853 \\
(0.2815)\end{array}$ & $\begin{array}{c}0.0174 * * * \\
(0.0020)\end{array}$ \\
\hline$I_{i, j}$ & $\begin{array}{c}-4.86 \mathrm{e}-7 * * * \\
(0.73 \mathrm{e}-7)\end{array}$ & $\begin{array}{c}-2.51 \mathrm{e}-8^{* *} \\
(1.19 \mathrm{e}-8)\end{array}$ & $\begin{array}{c}-3.78 \mathrm{e}-6 * \\
(2.64 \mathrm{e}-6)\end{array}$ & $\begin{array}{c}-5.41 \mathrm{e}-8 * * \\
(2.61 \mathrm{e}-8)\end{array}$ & $\begin{array}{c}-3.01 \mathrm{e}-7 * \\
(2.14 \mathrm{e}-7)\end{array}$ & $\begin{array}{l}-2.55 e-8 * \\
(1.94 e-8)\end{array}$ \\
\hline$C_{i, j}^{a g g}$ & $\begin{array}{c}1.05 \mathrm{e}-7^{* * *} \\
(1.11 \mathrm{e}-8)\end{array}$ & $\begin{array}{c}4.81 \mathrm{e}-8 * * * \\
(2.27 \mathrm{e}-8)\end{array}$ & $\begin{array}{c}6.53 \mathrm{e}-7 \\
(8.86 \mathrm{e}-7)\end{array}$ & $\begin{array}{c}2.51 \mathrm{e}-8 * * * \\
(8.80 \mathrm{e}-9)\end{array}$ & $\begin{array}{c}9.80 \mathrm{e}-7 \\
(1.44 \mathrm{e}-6)\end{array}$ & $\begin{array}{c}1.03 e-9 \\
(1.35 e-8)\end{array}$ \\
\hline$F F_{i, j}^{1}$ & $\begin{array}{c}0.8244 * * \\
(0.4413)\end{array}$ & $\begin{array}{l}0.0113^{*} \\
(0.0069)\end{array}$ & $\begin{array}{c}0.5389 * * \\
(0.2152)\end{array}$ & $\begin{array}{c}1.73 e-4 \\
(0.0073)\end{array}$ & $\begin{array}{l}0.5653^{*} \\
(0.4268)\end{array}$ & $\begin{array}{l}0.0075 * \\
(0.0047)\end{array}$ \\
\hline$F F_{i, j}^{2}$ & $\begin{array}{c}0.3393 \\
(0.5980)\end{array}$ & $\begin{array}{c}-0.0191 * * \\
(0.0066)\end{array}$ & $\begin{array}{c}-0.0890 \\
(0.8435)\end{array}$ & $\begin{array}{c}0.0021 \\
(0.0067)\end{array}$ & $\begin{array}{c}0.0369 \\
(0.5652)\end{array}$ & $\begin{array}{c}0.0025 \\
(0.0049)\end{array}$ \\
\hline$F F_{i, j}^{3}$ & $\begin{array}{c}0.1039 \\
(0.2227)\end{array}$ & $\begin{array}{c}0.0051 \\
(0.0050)\end{array}$ & $\begin{array}{c}0.7100 \\
(0.8457)\end{array}$ & $\begin{array}{c}-0.0038 \\
(0.0041)\end{array}$ & $\begin{array}{c}0.2654 \\
(0.5140)\end{array}$ & $\begin{array}{c}0.0044 \\
(0.0052)\end{array}$ \\
\hline $\mathrm{R}^{2}$ & 0.0994 & 0.2357 & 0.0785 & 0.1551 & 0.0429 & 0.1113 \\
\hline
\end{tabular}

Note: Bootstrapped standard errors are in parentheses. Asterisks indicate significance at $20 \%(*), 5 \%(* *)$, and $1 \%\left({ }^{* * *}\right) . F F_{i, j}^{k}$, with $k=1,2$ and 3, refer to the correlation between the Fama-French factors and the hedging costs from equation (1). 
Table 3

Summary statistics

\begin{tabular}{|c|c|c|c|c|c|}
\hline \multicolumn{6}{|c|}{ Panel A: Corn } \\
\hline & Spread & $I$ & $\gamma$ & $C^{a g g}$ & $C^{\text {curr }} / C^{\text {agg }}$ \\
\hline Mean & 0.0830 & 221,162 & 0.5192 & 595,725 & 0.8408 \\
\hline Median & 0.1050 & 243,833 & 0.6461 & 510,600 & 0.9133 \\
\hline Std. Dev. & 0.1083 & 85,554 & 0.3723 & 463,790 & 0.2073 \\
\hline Skewness & -4.4158 & -0.1698 & -0.2714 & 1.5315 & -1.6723 \\
\hline Kurtosis & 2.8248 & 2.3897 & 1.4090 & 5.6639 & 6.1384 \\
\hline Jarque-Bera & 0.0000 & 0.0000 & 0.0000 & 0.0000 & 0.0000 \\
\hline $\mathrm{ADF}$ & 0.0000 & 0.0933 & 0.0000 & 0.0424 & 0.0000 \\
\hline $\mathrm{AC}(1)$ & 0.9722 & 0.9938 & 0.9182 & 0.9945 & 0.9396 \\
\hline $\mathrm{AC}(10)$ & 0.7821 & 0.9352 & 0.3600 & 0.9089 & 0.5568 \\
\hline $\mathrm{AC}(50)$ & 0.1974 & 0.6926 & 0.1180 & 0.3412 & 0.3061 \\
\hline \multicolumn{6}{|c|}{ Panel B: Soy } \\
\hline & Spread & I & $\gamma$ & $C^{a g g}$ & $C^{\text {curr }} / C^{\text {agg }}$ \\
\hline Mean & 0.0256 & 100,270 & 0.5468 & 132,436 & 0.7254 \\
\hline Median & 0.0800 & 113,992 & 0.7162 & 85,971 & 0.9360 \\
\hline Std. Dev. & 0.3649 & 38,043 & 0.3852 & 130,272 & 0.4831 \\
\hline Skewness & -4.2511 & -0.5102 & -0.3602 & 1.0790 & -0.1828 \\
\hline Kurtosis & 5.9742 & 2.0270 & 1.4137 & 3.4578 & 5.0638 \\
\hline Jarque-Bera & 0.0000 & 0.0000 & 0.0000 & 0.0000 & 0.0000 \\
\hline ADF & 0.0000 & 0.1208 & 0.0000 & 0.0630 & 0.0000 \\
\hline $\mathrm{AC}(1)$ & 0.9571 & 0.9950 & 0.9195 & 0.9960 & 0.1154 \\
\hline $\mathrm{AC}(10)$ & 0.6478 & 0.9469 & 0.2199 & 0.9195 & 0.0041 \\
\hline $\mathrm{AC}(50)$ & 0.0320 & 0.7135 & -0.2094 & 0.3567 & -0.0001 \\
\hline \multicolumn{6}{|c|}{ Panel C: Wheat } \\
\hline & Spread & $I$ & $\gamma$ & $C^{a g g}$ & $C^{\text {curr }} / C^{\text {agg }}$ \\
\hline Mean & 0.1715 & 117,296 & 0.5250 & 59,771 & 0.8937 \\
\hline Median & 0.1450 & 126,536 & 0.6621 & 36,920 & 0.9061 \\
\hline Std. Dev. & 0.0923 & 41,821 & 0.3707 & 67,804 & 0.1814 \\
\hline Skewness & -0.9289 & -0.4748 & -0.2927 & 1.6185 & -2.8207 \\
\hline Kurtosis & 4.0515 & 2.4244 & 1.4155 & 5.0816 & 11.206 \\
\hline Jarque-Bera & 0.0000 & 0.0000 & 0.0000 & 0.0000 & 0.0000 \\
\hline $\mathrm{ADF}$ & 0.0062 & 0.0350 & 0.0000 & 0.0004 & 0.0000 \\
\hline $\mathrm{AC}(1)$ & 0.9654 & 0.9951 & 0.9410 & 0.9874 & 0.7836 \\
\hline $\mathrm{AC}(10)$ & 0.8195 & 0.9526 & -0.0713 & 0.8873 & 0.3295 \\
\hline $\mathrm{AC}(50)$ & 0.6000 & 0.8048 & 0.1266 & 0.1594 & 0.0043 \\
\hline
\end{tabular}

Note: Jarque-Bera refers to the probability that the distribution of the variable is normal, using the Jarque-Bera normality test (i.e., the null hypothesis is that of normality). ADF refers to the probability that the variable is nonstationary, using the Augmented Dickey-Fuller test, (i.e., where the null hypothesis is that of non-stationarity). $\mathrm{AC}(w)$ refers to the autocorrelation at lag $w . I$ refers to the CIT positions; $\gamma$ denotes the percentage of the CIT positions remaining in the nearby contract; $C^{a g g}$ is the aggregate cash position in the underlying product held by hedgers in both the this year's and next year's crop; $C^{c u r r} / C^{a g g}$ is the percentage of the hedgers' cash position in the current year's crop during the post-harvest period; Roll is the absolute value of the daily change in commodity index trader positions in the nearby contract. 
Table 4

Predicted signs and restrictions from the model

\begin{tabular}{cc}
\hline Coefficient & Predicted Sign \\
$\theta_{1}$ & + \\
$\theta_{2}$ & - \\
$\theta_{3}$ & - \\
$\theta_{4}$ & - \\
$\theta_{5}$ & - \\
$\theta_{6}$ & + \\
$\theta_{7}$ & + \\
$\theta_{8}$ & 0 \\
$\theta_{9}$ & - \\
\hline Restrictions & \\
$\theta_{1}+\theta_{3}$ & - \\
$\theta_{4}+\theta_{6}$ & + \\
\hline
\end{tabular}


Table 5

Estimation results - main model GARCH(1,1)

\begin{tabular}{|c|c|c|c|}
\hline \multicolumn{4}{|l|}{ Panel A } \\
\hline Conditional mean & Corn & Soy & Wheat \\
\hline \multirow{2}{*}{$\theta_{0}$} & $0.0213 * * *$ & $0.0258 * * *$ & $0.0760 * * *$ \\
\hline & $(0.0093)$ & $(0.0020)$ & $(0.0027)$ \\
\hline \multirow{2}{*}{$\theta_{1}\left(I_{t}\right)$} & $6.67 \mathrm{e}-7 * * *$ & $1.47 \mathrm{e}-6 * * *$ & $5.07 \mathrm{e}-7^{* * *}$ \\
\hline & $(3.38 \mathrm{e}-8)$ & $(1.56 \mathrm{e}-8)$ & $(1.40 \mathrm{e}-8)$ \\
\hline \multirow[t]{2}{*}{$\theta_{2}\left(\gamma_{t}\right)$} & $-0.0709 * * *$ & $-0.0269 * * *$ & $-0.0272 * * *$ \\
\hline & $(0.0142)$ & $(0.0031)$ & $(0.0024)$ \\
\hline \multirow{2}{*}{$\theta_{3}\left(\gamma_{t} I_{t}\right)$} & $-3.43 \mathrm{e}-7 * * *$ & $-3.83 \mathrm{e}-7 * * *$ & $-1.54 \mathrm{e}-7 * * *$ \\
\hline & $(4.16 e-8)$ & (2.46e-8) & $(1.42 \mathrm{e}-8)$ \\
\hline \multirow[t]{2}{*}{$\theta_{4}\left(C_{t}^{\text {curr }}\right)$} & $-1.14 \mathrm{e}-7 * * *$ & $-2.18 \mathrm{e}-7 * * *$ & $-2.98 \mathrm{e}-7 * * *$ \\
\hline & (1.08e-8) & (4.98e-8) & (3.18e-8) \\
\hline \multirow{2}{*}{$\theta_{5}\left(C_{t}^{\text {curr }} D_{t}^{\text {pre-harvest }}\right)$} & $-1.07 e-7 * * *$ & $-1.03 e-6 * * *$ & $-6.96 \mathrm{e}-7 * * *$ \\
\hline & $(1.04 \mathrm{e}-8)$ & $(8.14 \mathrm{e}-8)$ & (3.08e-8) \\
\hline \multirow{2}{*}{$\theta_{6}\left(C_{t}^{\text {curr }} D_{t}^{\text {post-harv }}\right)$} & $3.06 \mathrm{e}-7^{* * *}$ & $4.43 e-7 * * *$ & $3.90 \mathrm{e}-7^{* * *}$ \\
\hline & $(1.19 \mathrm{e}-8)$ & $(7.76 e-8)$ & $(2.98 \mathrm{e}-8)^{* * *}$ \\
\hline \multirow[t]{2}{*}{$\theta_{7}\left(\Lambda_{t}\right)$} & $8.03 e-5 * * *$ & $1.46 \mathrm{e}-5$ & $1.82 \mathrm{e}-4 * * *$ \\
\hline & $(1.58 \mathrm{e}-5)$ & (2.47e-5) & (5.18e-5) \\
\hline \multirow[t]{2}{*}{$\theta_{8}\left(\operatorname{Roll}_{t}\right)$} & $-7.37 e-7$ & $-1.44 \mathrm{e}-6 * * *$ & $-7.47 \mathrm{e}-7 * * *$ \\
\hline & $(6.32 \mathrm{e}-7)$ & $(1.23 e-7)$ & $(1.20 \mathrm{e}-7)$ \\
\hline \multirow{2}{*}{$\theta_{9}\left(C_{t}^{\text {next }} D_{t}^{\text {post-harv }}\right)$} & $-1.39 \mathrm{e}-7^{* * *}$ & $-3.26 \mathrm{e}-7^{* * *}$ & $-7.04 \mathrm{e}-7 * * *$ \\
\hline & $(2.64 \mathrm{e}-8)$ & $(2.45 \mathrm{e}-8)$ & $(1.17 \mathrm{e}-7)$ \\
\hline \multicolumn{4}{|l|}{ Panel B } \\
\hline \multicolumn{4}{|l|}{ Conditional variance } \\
\hline & $2.28 \mathrm{e}-4$ & $1.59 \mathrm{e}-4$ & $6.75 e-5$ \\
\hline \multirow[t]{2}{*}{$\omega_{1}\left(h_{t-1}\right)$} & $0.8496 * * *$ & $0.9209 * * *$ & $0.8182 * * *$ \\
\hline & $(0.0270)$ & $(0.0960)$ & $(0.0042)$ \\
\hline \multirow[t]{2}{*}{$\omega_{2}\left(\varepsilon_{t-1}^{2}\right)$} & $0.1008 * * *$ & $0.0776 * * *$ & $0.1737 * * *$ \\
\hline & $(0.0085)$ & (0.0096) & $(0.0061)$ \\
\hline \multirow[t]{2}{*}{$\omega_{3}\left(\Lambda_{t}\right)$} & $-2.84 \mathrm{e}-6^{* * *}$ & $-1.26 \mathrm{e}-6 * * *$ & $-1.08 \mathrm{e}-6^{* * *}$ \\
\hline & (2.23e-7) & (2.25e-7) & (6.97e-8) \\
\hline \multirow[t]{2}{*}{ GED } & $1.8613^{* * *}$ & $1.5110 * * *$ & $1.6817^{* * *}$ \\
\hline & $(0.0542)$ & $(0.0126)$ & $(0.0314)$ \\
\hline \multicolumn{4}{|l|}{ Panel C } \\
\hline \multicolumn{4}{|l|}{ Restrictions: } \\
\hline \multirow[t]{2}{*}{$\theta_{1}+\theta_{3}<0$} & $3.24 \mathrm{e}-7$ & $1.10 \mathrm{e}-6$ & 2.09e-7 \\
\hline & $(6.85 e-8)$ & $(1.64 \mathrm{e}-8)$ & (9.79e-8) \\
\hline \multirow[t]{2}{*}{$\theta_{4}+\theta_{6}>0$} & $1.92 \mathrm{e}-7 \dagger$ & $2.25 \mathrm{e}-7 \dagger$ & $0.92 \mathrm{e}-7 \dagger$ \\
\hline & $(2.44 \mathrm{e}-8)$ & $(6.29 \mathrm{e}-8)$ & $(1.13 \mathrm{e}-8)$ \\
\hline \multirow{3}{*}{$\begin{array}{l}R^{2} \\
\text { Log-Lik } \\
\text { \# of Obs. }\end{array}$} & 0.2386 & 0.1658 & 0.1902 \\
\hline & 2885.8 & 2837.8 & 3125.7 \\
\hline & 1761 & 1784 & 1768 \\
\hline \multicolumn{4}{|c|}{$\begin{array}{l}\text { Note: Standard errors are in parentheses. Asterisks indicate significance at } 5 \%(* *) \text { and } 1 \%(* * * \\
\text { respectively. } \dagger \text { indicates fail to reject the restriction. The estimated model is: }\end{array}$} \\
\hline \multirow{2}{*}{\multicolumn{4}{|c|}{$\begin{array}{c}S_{t}=\theta_{0}+\theta_{1} I_{t}+\theta_{2} \gamma_{t}+\theta_{3} \gamma_{t} I_{t}+\theta_{4} C_{t}^{\text {curr }}+\theta_{5} C_{t}^{\text {curr }} D_{t}^{\text {pre-harv }}+\theta_{6} C_{t}^{\text {curr }} D_{t}^{\text {post-harv }}+\theta_{7} \Lambda_{t} \\
+\theta_{8} \text { Roll }_{t}+\theta_{9} C_{t}^{\text {next }} D_{t}^{\text {post-harv }}+\varepsilon_{t}\end{array}$}} \\
\hline & & & \\
\hline & & & \\
\hline & $h_{t}=\omega_{0}+$ & $\begin{array}{lll}-1 & w_{3}{ }^{n}\end{array}$ & \\
\hline
\end{tabular}

$I_{t}$ refers to the CIT positions; $\gamma_{\mathrm{t}}$ denotes the percentage of the CIT position in the nearby contract; $C_{t}^{\text {curr }}$ is this year (current) cash position in the underlying product held by hedgers; $C_{t}^{\text {next }}$ is next year cash position in the underlying product held by hedgers; Roll $t$ indicates the amount of roll-over by CIT and is computed as the absolute value of the daily change in commodity index trader positions in the nearby contract; $\Lambda_{\mathrm{t}}$ is the number of days until contract expiration; $D_{t}^{\text {pre-harv. }}$ and $D_{t}^{\text {post-harv. }}$ are dummy variables indicating the pre-harvest and the post-harvest contracts, respectively. 


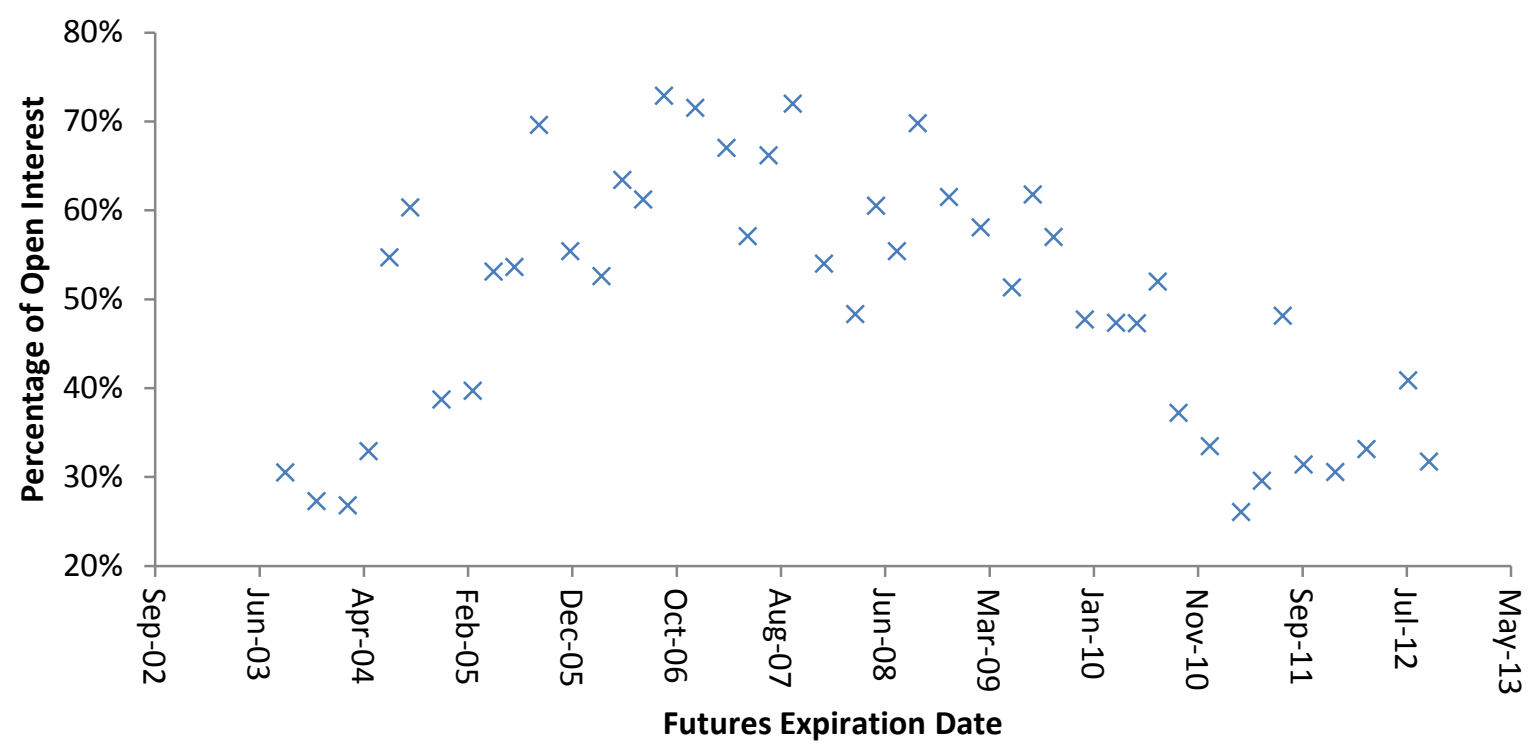

Figure 1 - Corn: Aggregate CIT positions in the nearby contract as a percentage of open interest 


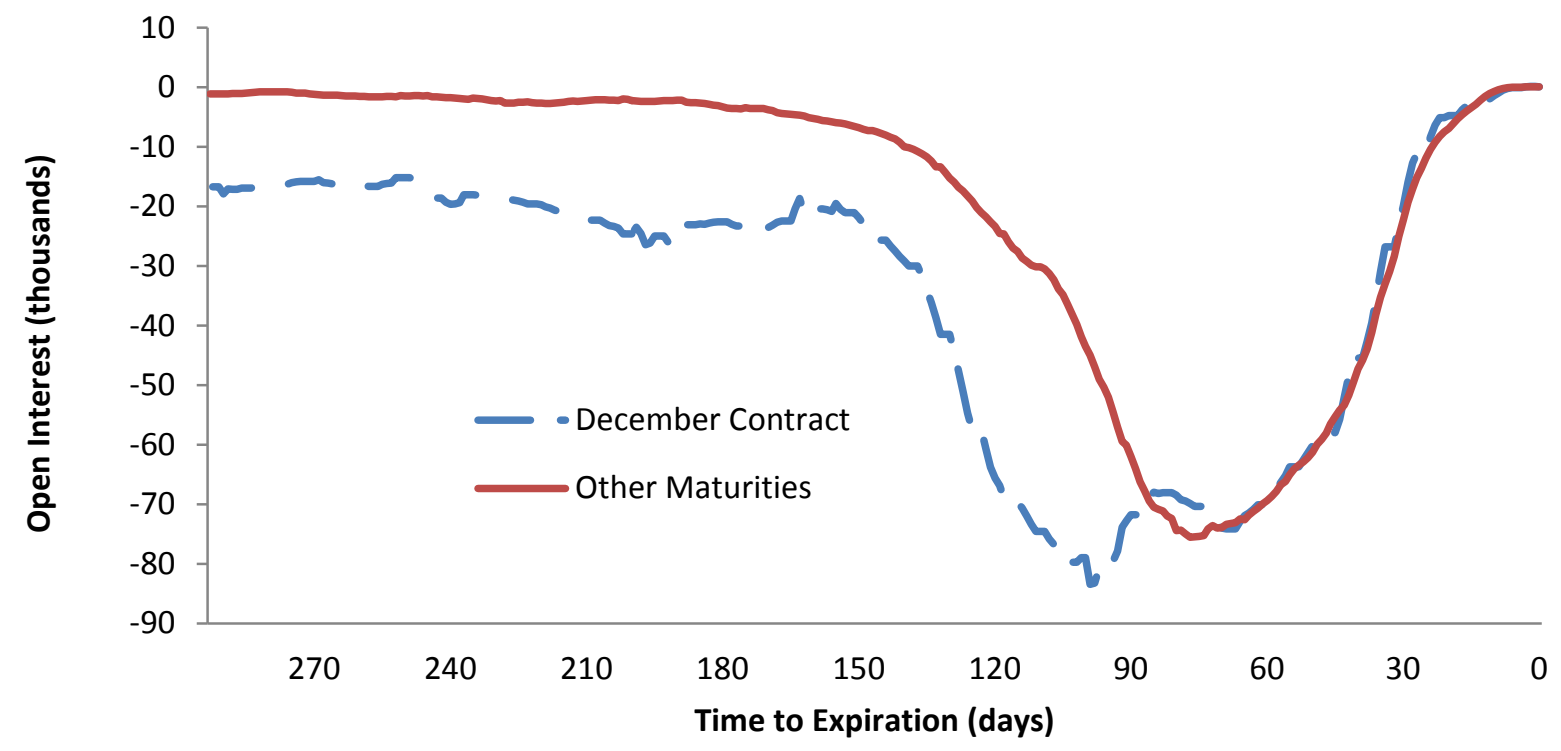

Figure 2 - Wheat: Distributor average positions in the December contracts, and other maturities. Note: On the $\mathrm{x}$-axis, 0 is the expiration date of the contract.

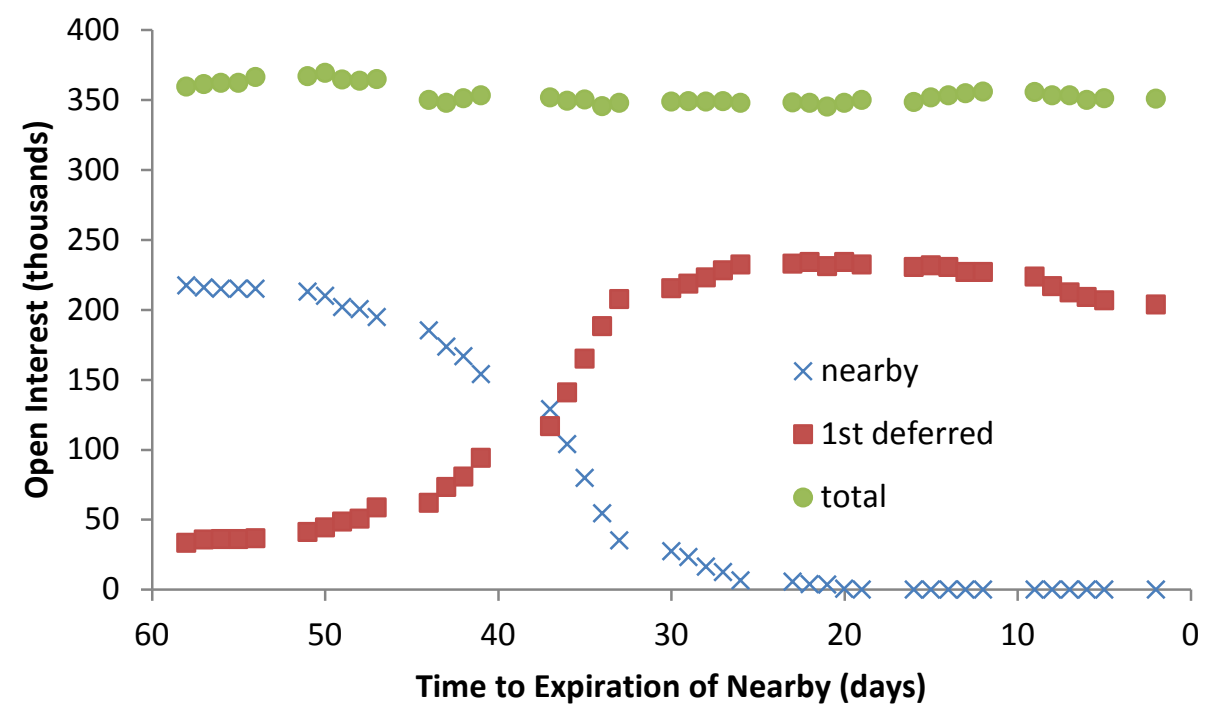

\section{Figure 3A}

Corn: CIT positions in the May 2007contract (nearby), July 2007 contract (1st-deferred) and sum of the two (total). On the horizontal axis, 0 is the expiration of the contract. 


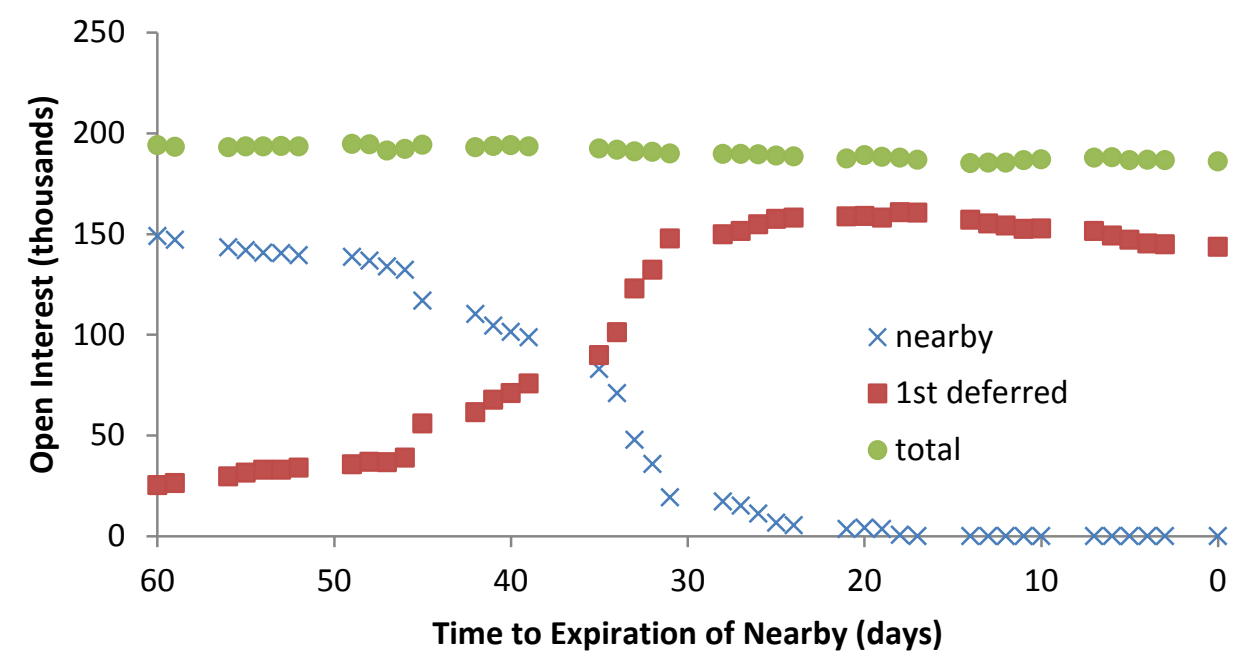

\section{Figure 3B}

Wheat: CIT positions in the May 2007contract (nearby), July 2007 contract (1st-deferred) and sum of the two (total). On the horizontal axis, 0 is the expiration of the contract.

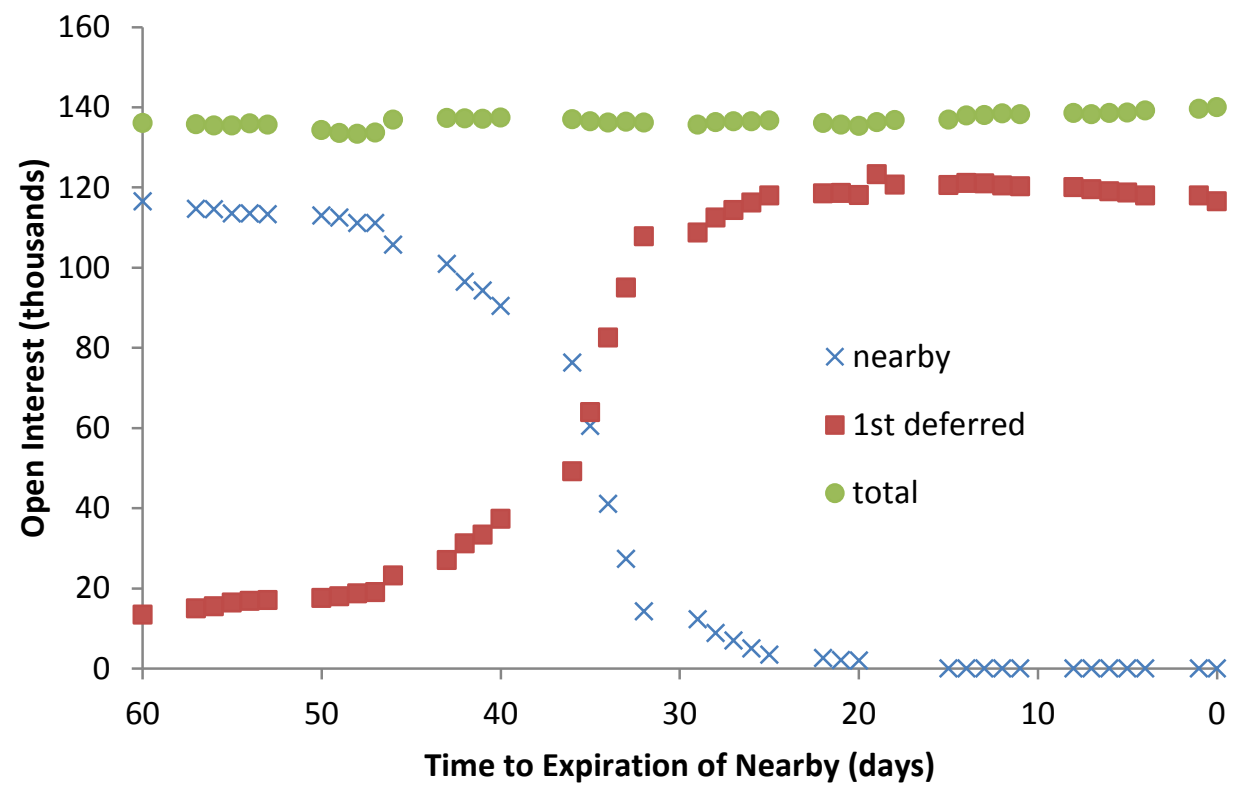

\section{Figure 3C}

Soy: CIT positions in the May 2007contract (nearby), July 2007 contract (1st-deferred) and sum of the two (total). On the horizontal axis, 0 is the expiration of the contract. 


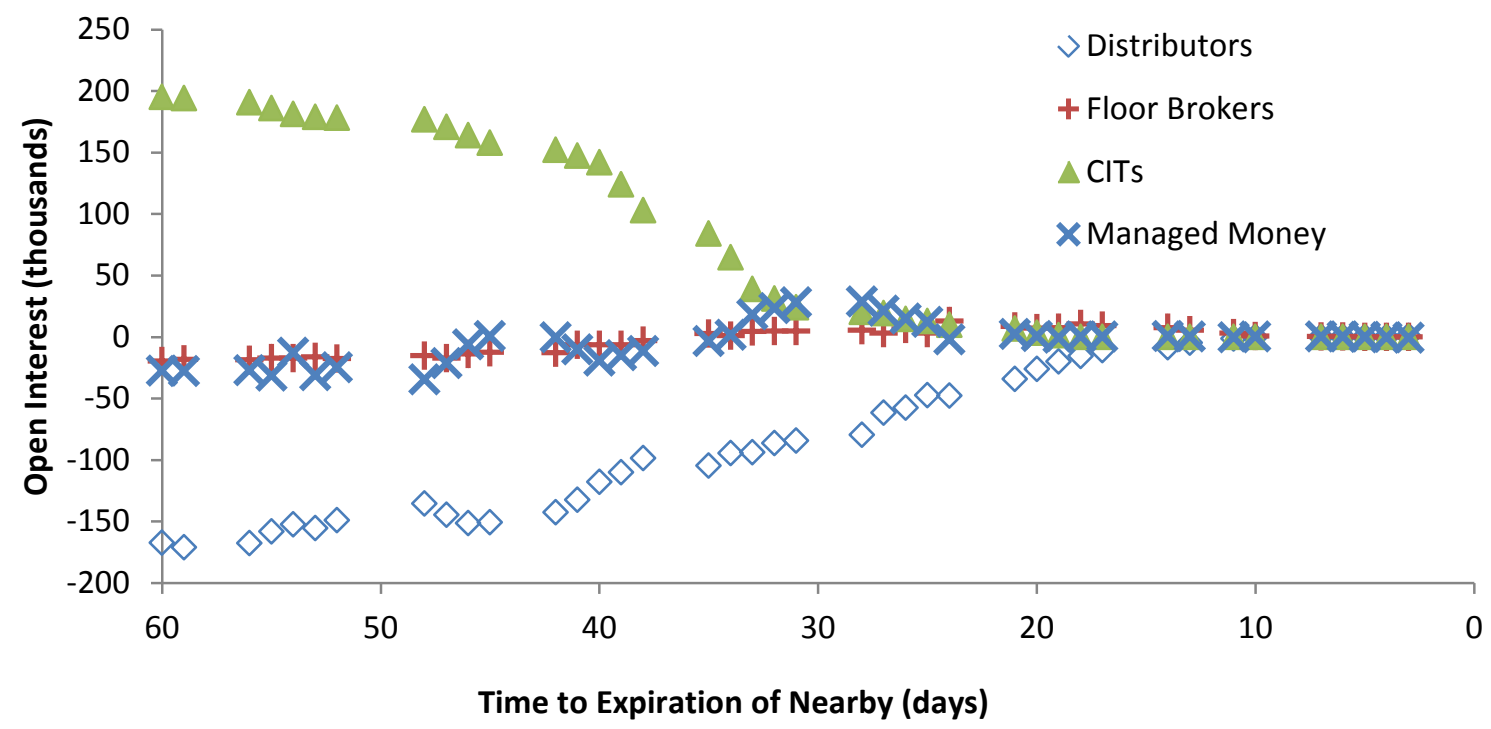

Figure 4 Corn: Average positions of distributors, floor brokers, commodity index traders (CITs), and managed money traders.

On the $\mathrm{x}$-axis, 0 is the expiration date of the contract. 


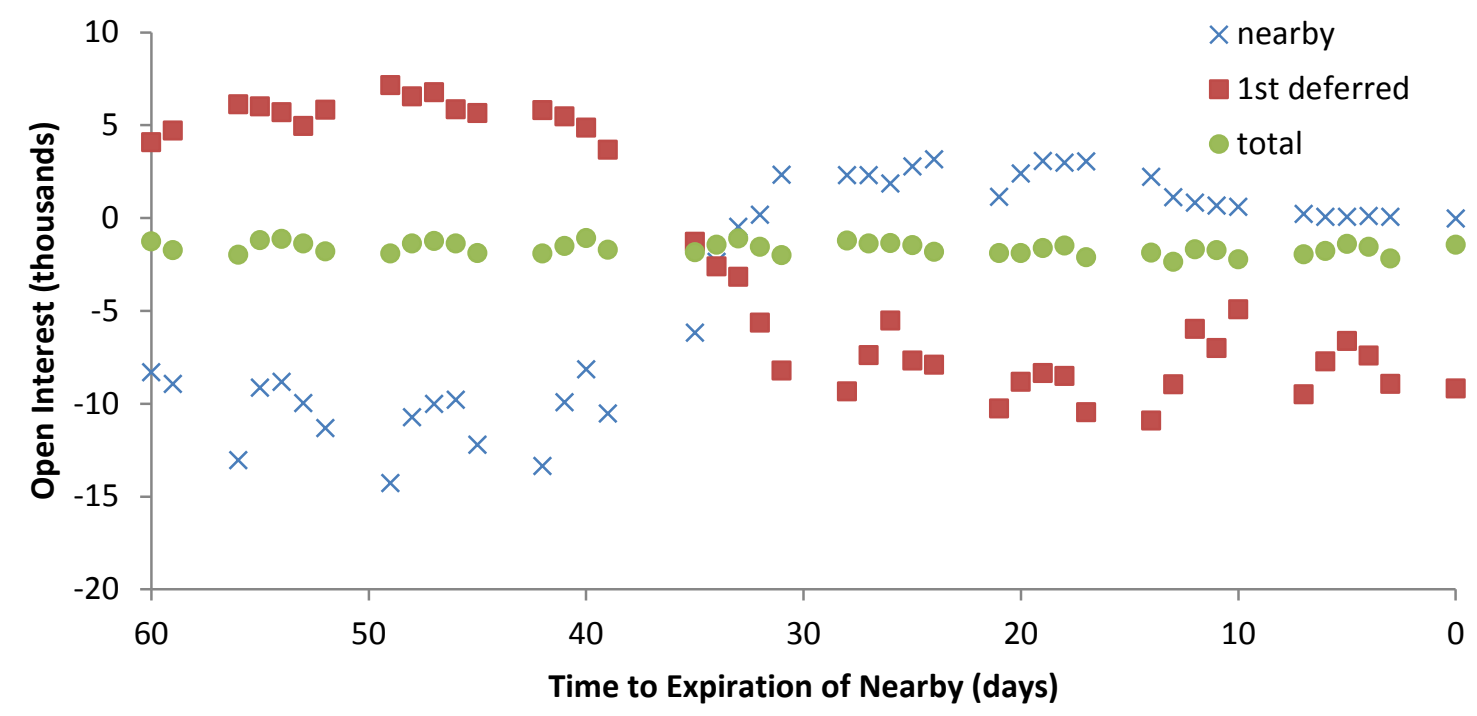

Figure 5 - Wheat: Average market maker/local positions in the nearby contract, $1^{\text {st }}$-deferred contract, and across all maturities (total).

On the $\mathrm{x}$-axis, 0 is the expiration date of the contract. 


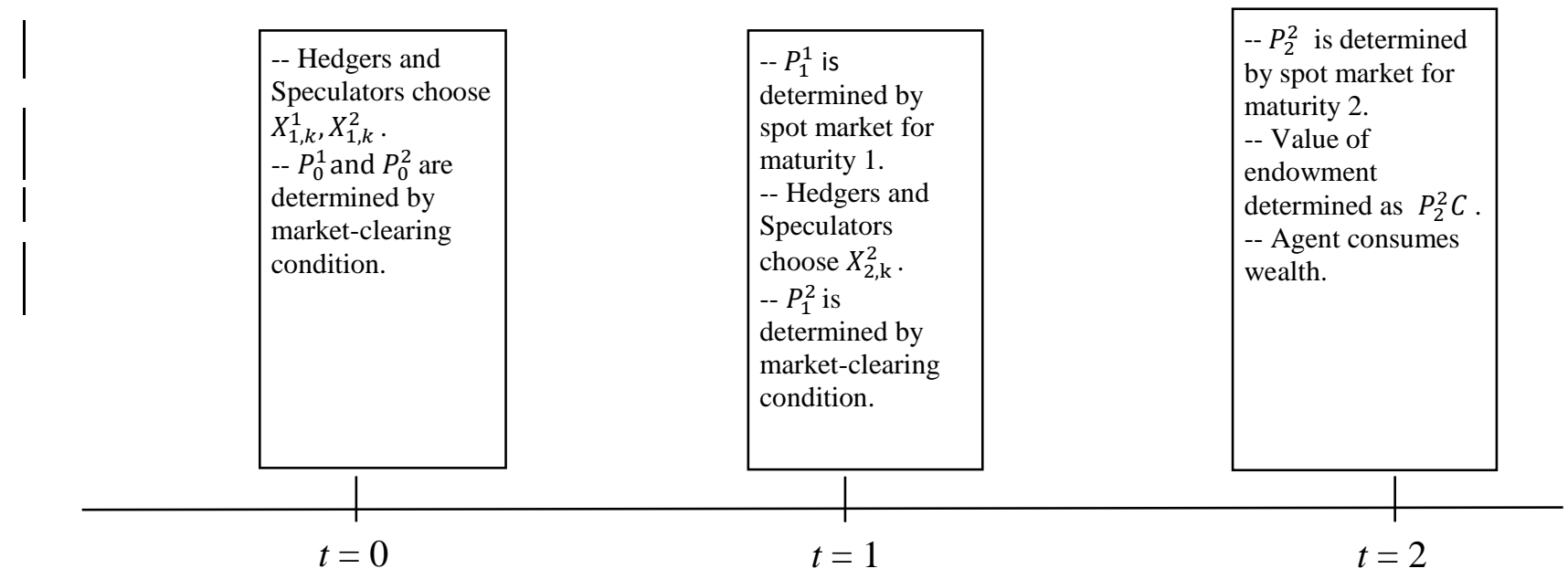

Figure 6 - Timing of decisions 


\section{Appendix}

In this Appendix, we generalize the model through two extensions, in order to derive a richer set of implications for prices. One artifact of the two-period model in the text is that index traders are active in all traded contracts in all periods. Generalizing the model to three periods allows us to examine what happens when the maturities that hedgers wish to trade differ from those for which index traders take positions. As in the two-period model, we assume hedgers each have an endowment of the physical product of size $C$ that they will receive in the final period, and the price they will receive for the physical will be determined at that time. The optimization at $t=0$ is now:

$$
\begin{gathered}
U\left[W_{0}+X_{2}^{3}\left(P_{2}^{3}-P_{1}^{3}\right)+X_{3}^{3}\left(P_{3}^{3}-P_{2}^{3}\right)+X_{2}^{2}\left(P_{2}^{2}-P_{1}^{2}\right)+\left(P_{3}^{3}\right) C_{k}+X_{1}^{2}\left(P_{1}^{2}-P_{0}^{2}\right)+\right. \\
\left.X_{1}^{3}\left(P_{1}^{3}-P_{0}^{3}\right)+X_{1}^{1}\left(P_{1}^{1}-P_{0}^{1}\right)\right]
\end{gathered}
$$

Using the same kind of backward induction as in the text, the equilibrium at $t=2$ and $t=$ 3 are the same as those in equations (6), (9), and (10) (recognizing that the terminal period is now $t=3$ rather than $t=2$, and the period preceding the final period is now $t=2$, rather than $t=$ 1). There are now three contracts traded at $t=0$, and some additional notation is required to adjust to this change. Specifically, let $I_{i}^{j}$ be index trader positions in contract $j$ at time $i$ (so that $I_{i}=\sum_{j=1}^{3} I_{i}^{j}$ ). Each trader's first-order conditions with respect to their positions in the three contracts $\left(X_{1}^{1}, X_{1}^{2}\right.$, and $\left.X_{1}^{3}\right)$ are now:

$$
\begin{gathered}
\left(\sigma_{1}^{1}\right)^{2} X_{1, k}^{1}+\sigma_{1}^{12} X_{1, k}^{2}+\sigma_{1}^{13} X_{1, k}^{3} \\
=\frac{E_{0}\left[P_{1}^{1}-P_{0}^{1}\right]}{\alpha}-\sigma_{13}^{13}\left(X_{3, k}^{3}+C_{k}\right)-\sigma_{12}^{13}\left(X_{2, k}^{3}-X_{3, k}^{3}\right)-\sigma_{12}^{12} X_{2, k}^{2} \\
\quad+\sigma_{1}^{12} X_{2, k}^{2}+\sigma_{1}^{13} X_{2, k}^{3}
\end{gathered}
$$




$$
\begin{gathered}
\sigma_{1}^{12} X_{1, k}^{1}+\left(\sigma_{1}^{2}\right)^{2} X_{1, k}^{2}+\sigma_{1}^{23} X_{1, k}^{3} \\
=\frac{E_{0}\left[P_{1}^{2}-P_{0}^{2}\right]}{\alpha}-\sigma_{13}^{23}\left(X_{3, k}^{3}+C_{k}\right)-\sigma_{12}^{23}\left(X_{2, k}^{3}-X_{3, k}^{3}\right)-\sigma_{12}^{2} X_{2, k}^{2} \\
+\sigma_{1}^{23} X_{2, k}^{3}+\left(\sigma_{1}^{2}\right)^{2} X_{2, k}^{2} \\
\sigma_{1}^{13} X_{1, k}^{1}+\sigma_{1}^{23} X_{1, k}^{2}+\left(\sigma_{1}^{3}\right)^{2} X_{1, k}^{3}=\frac{E_{0}\left[P_{1}^{3}-P_{0}^{3}\right]}{\alpha}-\sigma_{13}^{3}\left(X_{3, k}^{3}+C_{k}\right)-\sigma_{12}^{3}\left(X_{2, k}^{3}-X_{3, k}^{3}\right)-\sigma_{12}^{23} X_{2, k}^{2} \\
+\sigma_{1}^{23} X_{2, k}^{2}+\left(\sigma_{1}^{3}\right)^{2} X_{2, k}^{3} .
\end{gathered}
$$

From the analysis in the text, we know that $X_{i, S}^{3}=X_{i, H}^{3}+C$ for $i=2,3$, and $X_{2, S}^{2}=X_{2, H}^{2}$, which means that the terms involving $X_{i, k}^{j}$ on the right-hand sides of equations (A.1) - (A.3) are each the same for hedgers and market-makers, with the exception of $X_{i, k}^{3}$ (which differs by $C$ between $S$ and $H$ ). Solving this system of equations shows that $X_{1, S}^{3}=X_{1, H}^{3}+C$, and $X_{i, S}^{j}=X_{i, H}^{j}$ for $j=1,2$. We can then use the market-clearing conditions to find that $X_{1, H}^{3}=\frac{-\left(I_{1}^{3}+N_{S} C\right)}{N_{S}+N_{H}}$ and $X_{1, H}^{j}=\frac{-I_{1}^{j}}{N_{S}+N_{H}}, j=1,2$ (while noting that $I_{1}^{3}=0$ by assumption). Hence, we find that unlike the case when there are only two periods, some of the $X_{1}^{j}$ are functions of $C$, while others are functions of $I_{1}^{j}$. An implication of this property is that future trading behavior of CITs (i.e., in deferred contracts) will impact the initial prices of those contracts. The empirical counterpart of this implication is that the prices of the deferred contract will be affected by CITs announcements, even before the CIT makes any actual trades in the deferred contracts.

Two additional implications of this analysis are that we expect the spread to be decreasing in $C$, and that this conclusion will be true under more general conditions in period 1 
than period 0 . In that sense, the prediction is that $\frac{\partial S_{0}}{\partial C}$ will be smaller (i.e., more negative) in postharvest periods:

$$
\begin{aligned}
& \frac{\partial S_{0}}{\partial C}= \\
& \frac{1}{N_{H}+N_{S}}\left[\left(\sigma_{1}^{13}-\sigma_{1}^{23}\right) N_{S}+\left(N_{H}\right)\left(\sigma_{13}^{13}-\sigma_{13}^{23}\right) R_{2}+N_{S} R_{1}\left(\sigma_{1}^{23}-\sigma_{1}^{13}\right)-N_{S}\left(R_{1}\right.\right. \\
& \left.\left.-R_{2}\right)\left(\sigma_{12}^{13}-\sigma_{12}^{23}\right)\right] \\
& \frac{\partial S_{1}}{\partial C}=\frac{1}{N_{H}+N_{S}}\left[\left(\left(\sigma_{2}^{3}\right)^{2}-\sigma_{2}^{23}\right) N_{S}+\left(N_{H}\right)\left(\sigma_{23}^{23}-\sigma_{23}^{3}\right) R_{2}+N_{S} R_{2}\left(\sigma_{2}^{23}-\left(\sigma_{2}^{3}\right)^{2)}\right]\right. \\
& =\frac{1}{N_{H}+N_{S}}\left[N_{S}\left(R_{2}-1\right)\left(\sigma_{2}^{23}-\left(\sigma_{2}^{3}\right)^{2}+N_{H}\left(\sigma_{23}^{23}-\sigma_{23}^{3}\right)\right)\right] .
\end{aligned}
$$

$\frac{\partial S_{1}}{\partial C}$ will be negative if $R_{2} \geq 1$ and $\sigma_{23}^{3}>\sigma_{23}^{23}$. The latter condition seems reasonable, since we expect the correlation between movements in the period 2 and period 3 futures prices to be tighter between a single maturity than adjacent maturities. $\frac{\partial S_{0}}{\partial C}$ will be negative under similar conditions, but requires additional assumptions. In that sense, the prediction that $\frac{\partial S_{1}}{\partial C}<0$ is stronger than the prediction that $\frac{\partial S_{0}}{\partial C}<0$. In our empirical work, we allow the effect of a hedger's cash positions on the spread to vary over the harvest cycle.

The other extension we wish to consider involves multiple endowments. The basic model in Section IV features an endowment that is realized (i.e., priced) as of the final period. As such, it does not allow one to consider pricing behavior over the course of a period following the valuation of the endowment. To examine that, we modify the model to allow hedgers to have endowments in two periods ( $t=1$ and $t=3)$. This corresponds to an environment in which the 
market has a periodic change in supply or demand (e.g., an annual harvest). ${ }^{37}$ Specifically, suppose the hedger has a crop that will mature in period $1\left(C^{\text {curr }}\right)$ as well as period $3\left(C^{\text {next }}\right)$, and also consumes some of his wealth in period $1(\varphi)$. We can think of periods 1 and 3 as the post-harvest periods in consecutive years. We now can write his utility function as:

$$
\begin{gathered}
U\left[W_{0}+X_{2}^{3}\left(P_{2}^{3}-P_{1}^{3}\right)+X_{3}^{3}\left(P_{3}^{3}-P_{2}^{3}\right)+X_{2}^{2}\left(P_{2}^{2}-P_{1}^{2}\right)+\left(P_{3}^{3}\right) C_{k}^{\text {next }}+X_{1}^{2}\left(P_{1}^{2}-P_{0}^{2}\right)+\right. \\
\left.X_{1}^{3}\left(P_{1}^{3}-P_{0}^{3}\right)+X_{1}^{1}\left(P_{1}^{1}-P_{0}^{1}\right)+P_{1}^{1} C_{k}^{\text {Curr }}-\varphi_{k}\right]+U\left[\varphi_{k}\right] .
\end{gathered}
$$

The optimization at $t=2$ is identical to that characterized in equation (4), except that the hedger's wealth at $t=3$ increases by $P_{1}^{1} C_{k}^{c u r r}$ and decreases by $\varphi_{k}$, relatively to his wealth at $t=$ 2 in equation (4). Since those changes do not affect the first-order conditions at $t=1$ and $t=2$, they do not alter the optimal choice of $X_{i}^{j}$ in those periods, and hence do not affect $P_{j}^{i}$ in those periods.

The choice of $\varphi$ at $t=1$ involves a first-order condition of the general form:

$$
\int \exp \left(-\left(\alpha\left(W_{0}-\varphi\right)+P_{3}^{3} C\right)\right) f\left(P_{3}^{3}\right) d P_{3}^{3}=\exp -(\alpha \varphi)
$$

(i.e., equating the marginal utility of income in the two periods).

Finally, consider the choice of positions at $t=0$. The first-order conditions with respect to positions are similar to those in equations (A.1) - (A.3):

$$
\begin{gathered}
\left(\sigma_{1}^{1}\right)^{2} X_{1, k}^{1}+\sigma_{1}^{12} X_{1, k}^{2}+\sigma_{1}^{13} X_{1, k}^{3}=\frac{E_{0}\left[P_{1}^{1}-P_{0}^{1}\right]}{\alpha}-\sigma_{13}^{13}\left(X_{3, k}^{3}+C_{k}^{\text {next }}\right)-\sigma_{12}^{13}\left(X_{2, k}^{3}-X_{3 k}^{3}\right)- \\
\sigma_{12}^{12} X_{2, k}^{2}+\sigma_{1}^{12} X_{2, k}^{2}+\sigma_{1}^{13} X_{2, k}^{3}-\left(\sigma_{1}^{1}\right)^{2} C_{k}^{\text {curr }}(\text { A.1' })
\end{gathered}
$$

37 While this interpretation would be more complete in a four-period model (so that endowments are receiving every second period), no additional insight would be obtained from that model, while it would add considerable notational clutter. 


$$
\begin{gathered}
\sigma_{1}^{12} X_{1, k}^{1}+\left(\sigma_{1}^{2}\right)^{2} X_{1, k}^{2}+\sigma_{1}^{23} X_{1, k}^{3}=\frac{E_{0}\left[P_{1}^{2}-P_{0}^{2}\right]}{\alpha}-\sigma_{13}^{23}\left(X_{3, k}^{3}+C_{k}^{\text {next }}\right)-\sigma_{12}^{23}\left(X_{2, k}^{3}-X_{3, k}^{3}\right)- \\
\sigma_{12}^{2} X_{2, k}^{2}+\sigma_{1}^{23} X_{2, k}^{3}+\left(\sigma_{1}^{2}\right)^{2} X_{2, k}^{2}-\sigma_{1}^{12} C_{k}^{\text {curr }}\left(\text { A. } 2^{\prime}\right) \\
\sigma_{1}^{13} X_{1, k}^{1}+\sigma_{1}^{23} X_{1, k}^{2}+\left(\sigma_{1}^{3}\right)^{2} X_{1, k}^{3}=\frac{E_{0}\left[P_{1}^{3}-P_{0}^{3}\right]}{\alpha}-\sigma_{13}^{3}\left(X_{3, k}^{3}+C_{k}^{\text {next }}\right)-\sigma_{12}^{3}\left(X_{2, k}^{3}-X_{3, k}^{3}\right)- \\
\sigma_{12}^{23} X_{2, k}^{2}+\sigma_{1}^{23} X_{2, k}^{2}+\left(\sigma_{1}^{3}\right)^{2} X_{2, k}^{3}-\sigma_{1}^{13} C_{k}^{\text {curr }} .
\end{gathered}
$$

As above, we can use the relationship $X_{i, H}^{3}=X_{i, S}^{3}-C^{\text {next }}$ for $i=2,3$, along with (A.1') - (A.3') to derive the relationship between $X_{1, H}^{j}$ and $X_{1, S}^{j}: X_{1, H}^{1}=X_{1, S}^{1}-C^{c u r r}, X_{1, H}^{2}=X_{1, S}^{2}$ and $X_{1, H}^{3}=$ $X_{1, S}^{3}-C^{\text {next }}$

It follows that using the market-clearing condition and (A.1') - (A.3'), we can express prices in terms of the exogenous variables, $I, C^{\text {next }}$, and $C^{\text {curr }}$.

This yields one additional implication: the spread in period 0 will be increasing in $C^{\text {curr }}$ :

$$
\frac{\partial S_{0}}{\partial C^{c u r r}}=\left[\left(\sigma_{1}^{1}\right)^{2}-\sigma_{1}^{12}\left[1-\frac{N_{H}}{N_{H}+N_{S}}\right]>0 .\right.
$$

That is, the spread in the post-harvest period will be increasing in a hedger's current-year physical positions. 